OPEN ACCESS

Edited by: Matilde Alique,

University of Alcalá, Spain

Reviewed by:

Jiayu Zhang,

Chinese Academy of Sciences, China

Jose A Garcia-Salcedo,

Andalusian Autonomous Government of Genomics and Oncological

Research (GENYO), Spain

*Correspondence: Jose Felix Moruno-Manchon Jose.felix.morunomanchon@ uth.tmc.edu

Specialty section: This article was submitted to Molecular Mechanisms of Aging,

a section of the journal

Frontiers in Aging

Received: 18 October 2021 Accepted: 07 December 2021

Published: 12 January 2022

Citation:

Noh B, Blasco-Conesa MP Lai Y-J Ganesh BP, Urayama A, Moreno-Gonzalez I, Marrelli SP, McCullough LD and

Moruno-Manchon JF (2022) G-

quadruplexes Stabilization

Upregulates CCN1 and Accelerates

Aging in Cultured Cerebral Endothelial Cells.

Front. Aging 2:797562

doi: 10.3389/fragi.2021.797562

\section{G-quadruplexes Stabilization} Upregulates CCN1 and Accelerates Aging in Cultured Cerebral Endothelial Cells

Brian Noh', Maria P. Blasco-Conesa ${ }^{1}$, Yun-Ju Lai ${ }^{1,2}$, Bhanu Priya Ganesh ${ }^{1}$, Akihiko Urayama ${ }^{1}$, Ines Moreno-Gonzalez ${ }^{1,3,4}$, Sean P. Marrelli ${ }^{1}$, Louise D. McCullough ${ }^{1}$ and Jose Felix Moruno-Manchon ${ }^{1 *}$

${ }^{1}$ Department of Neurology, McGovern Medical School at the University of Texas Health Science Center at Houston, Houston, TX, United States, ${ }^{2}$ Solomont School of Nursing, Zuckerberg College of Health Sciences, University of Massachusetts Lowell, Lowell, MA, United States, ${ }^{3}$ Department of Cell Biology, Faculty of Sciences, Instituto de Investigacion Biomedica de Malaga-IBIMA, Malaga University, Malaga, Spain, ${ }^{4}$ Networking Biomedical Research Networking Center on Neurodegenerative Diseases (CIBERNED), Madrid, Spain

Senescence in the cerebral endothelium has been proposed as a mechanism that can drive dysfunction of the cerebral vasculature, which precedes vascular dementia. Cysteine-rich angiogenic inducer 61 (Cyr61/CCN1) is a matricellular protein secreted by cerebral endothelial cells (CEC). CCN1 induces senescence in fibroblasts. However, whether CCN1 contributes to senescence in $\mathrm{CEC}$ and how this is regulated requires further study. Aging has been associated with the formation of four-stranded Guaninequadruplexes (G4s) in G-rich motifs of DNA and RNA. Stabilization of the G4 structures regulates transcription and translation either by upregulation or downregulation depending on the gene target. Previously, we showed that aged mice treated with a G4-stabilizing compound had enhanced senescence-associated (SA) phenotypes in their brains, and these mice exhibited enhanced cognitive deficits. A sequence in the $3^{\prime}$-UTR of the human CCN1 mRNA has the ability to fold into G4s in vitro. We hypothesize that G4 stabilization regulates CCN1 in cultured primary CEC and induces endothelial senescence. We used cerebral microvessel fractions and cultured primary CEC from young (4-months old, m/o) and aged (18-m/o) mice to determine CCN1 levels. SA phenotypes were determined by high-resolution fluorescence microscopy in cultured primary CEC, and we used Thioflavin T to recognize RNA-G4s for fluorescence spectra. We found that cultured CEC from aged mice exhibited enhanced levels of SA phenotypes, and higher levels of CCN1 and G4 stabilization. In cultured CEC, CCN1 induced SA phenotypes, such as SA $\beta$-galactosidase activity, and double-strand DNA damage. Furthermore, CCN1 levels were upregulated by a G4 ligand, and a G-rich motif in the 3'-UTR of the Ccn1 mRNA was folded into a G4. In conclusion, we demonstrate that CCN1 can induce senescence in cultured primary CEC, and we provide evidence that G4 stabilization is a novel mechanism regulating the SASP component CCN1.

Keywords: senescence, endothelial cells, G-quadruplex, aging, CCN1 


\section{INTRODUCTION}

The blood-brain barrier (BBB) is the physical barrier between the brain parenchyma and the periphery (Wang et al., 2018). It is formed by cerebral endothelial cells (CEC), pericytes, astrocytes, and smooth muscle cells. A healthy cerebrovascular endothelium is essential to maintain low and selective permeability of the BBB (Chen and Liu 2012), which allows both proper nutrient delivery to the brain and protection from infections. However, dysfunction of CEC can contribute to BBB disruption (Jia et al., 2019). Thus, identifying molecular mechanisms that can promote endothelial damage is critical for our understanding of cerebral endothelium dysfunction, and to guide us in developing new therapeutic strategies to preserve $\mathrm{BBB}$ function.

During aging, CEC enter into a non-proliferative state named senescence. This state is characterized by enhanced DNA damage (Lahteenvuo and Rosenzweig 2012) and secretion of proinflammatory cytokines that induce senescence in neighboring cells (Tchkonia et al., 2013). This "senescent-associated secretory phenotype (SASP)" in CEC contributes to cerebral endothelium dysfunction and dementia (Wang et al., 2018; Graves and Baker 2020). This senescence phenotype adversely affects the cerebral vasculature in a multifaceted manner (Pelegri et al., 2007; Del Valle et al., 2009; Yamazaki et al., 2016; Graves and Baker 2020). Currently, the agents that induce CEC senescence are poorly defined.

The extracellular matrix protein cysteine-rich angiogenic inducer 61 (Cyr61/CCN1) participates in a wide variety of functions, such as promoting cell survival, cell proliferation, angiogenesis and wound repair. However, CCN1 has also been shown to promote senescence in fibroblasts (Jun and Lau 2010) and is one of the characteristic SASP genes. In the brain, CCN1 is produced and secreted by endothelial cells and astrocytes. Recently, it was found that Ccnl is the most highly upregulated gene in senescence-induced astrocytes, but not in reactive astrocytes (Simmnacher et al., 2020), highlighting its specific role in cellular senescence. Whether the SASP factor CCN1 contributes to senescence specifically in CEC and how CCN1 is regulated warrants further study.

Aging is associated with the formation of four-stranded Guanine-quadruplexes (G4s) in guanine-rich motifs of DNA and RNA (Lejault et al., 2020; Moruno-Manchon et al., 2020; Teng et al., 2020). Hoogsteen hydrogen bonds align four guanines in a sequence in a planar tetrad, and several tetrads can be stacked in one single G4. Growing evidence in living cells indicates that G4 stabilization regulates transcription (Siddiqui-Jain et al., 2002; Agarwal et al., 2014; Armas et al., 2017; Moruno-Manchon et al., 2017; Lejault et al., 2020; Moruno-Manchon et al., 2020) and translation (Schaeffer et al., 2001; Khateb et al., 2007), either upregulating or downregulating expression depending on the gene target (Armas et al., 2017; Fay et al., 2017). G4s are also involved in RNA splicing (Zhang et al., 2019), mRNA subcellular localization (Subramanian et al., 2011), and DNA integrity (Kruisselbrink et al., 2008; Castillo Bosch et al., 2014;
Moruno-Manchon et al., 2017; Techer et al., 2017). Previously, we found that treating aged mice with a G4-stabilizing compound led to enhanced SA phenotypes in the brain (DNA damage and lipofuscin accumulation), compared with age-matched controls (Moruno-Manchon et al., 2020). Mice treated with a G4-stabilizer also exhibited enhanced cognitive deficits in comparison to control mice (Moruno-Manchon et al., 2020). We further demonstrated that stabilizing G4s induced DNA damage in cultured neurons (Moruno-Manchon et al., 2017) and contributed to impairment of autophagy, which is associated with senescence (Moreno-Blas et al., 2019; Salazar et al., 2020; Sunderland et al., 2020). In addition, G4 stabilization induced DNA damage in cultured astrocytes and microglia (Lejault et al., 2020; Moruno-Manchon et al., 2020; Tabor et al., 2021). Thus, the stability of G4 structures appears to have a wide influence in cells relevant to the development of dementia.

In this study, we show that CCN1 is upregulated in cultured primary CEC derived from aged mice compared with those derived from young mice. Treating CEC with a recombinant CCN1 protein exacerbated SA phenotypes in cultured CEC from aged mice. CCN1 levels were upregulated by a G4 stabilizing drug, which promoted CEC senescence. Finally, we propose that CCN1 levels increase by the stabilization of G4 in a motif found in the $3^{\prime}$-UTR of the Con 1 mRNA. Thus, our study highlights the role of $\mathrm{CCN} 1$ in contributing to endothelial senescence and proposes a novel mechanism by which SASP component CCN1 is regulated.

\section{MATERIALS AND METHODS}

\section{Animals and Ethics Statement}

3-4 and 18-20 months old (m/o) C57BL/6J female mice were obtained from Jackson laboratories and raised in the animal facilities at the University of Texas McGovern Medical School. The experiments were conducted following the protocol approved by the Center for Laboratory Medicine and Care (CLAMC, protocol number AWC-21-0084) at the University of Texas McGovern Medical School. Mice were maintained in an environment with constant temperature and humidity on a $12 \mathrm{~h}$ light $/ 2 \mathrm{~h}$ dark schedule, and with ad libitum access to water and mouse lab pellets. Researchers and veterinarians manipulated mice with no distress, pain, or injury.

\section{Antibodies and Reagents}

Antibodies against CCN1 were obtained from Santa Cruz Technologies (\#sc-374129). Antibodies against p16 ${ }^{\mathrm{INK} 4 \mathrm{~A}}$ were from Biomatik (\#CAF10165). Antibodies against BG4 were from Sigma-Millipore (\#MABE917). Antibodies against CD31 (\#ab28364), $\gamma \mathrm{H} 2 \mathrm{AX}$ (\#ab11174), and $\beta$-Tubulin (\#ab7751) were from Abcam.

Recombinant Cyr61/CCN1 protein was from Novus Biologicals (\#NBP2-34944). Pyridostatin was purchased from Cayman (\#18013). Thioflavin $\mathrm{T}$ was purchased from Sigma-Aldrich (\#T3516). RNA oligos were purchased from Sigma-Millipore (\#VC40001). Hoechst dye was from Santa Cruz Biotechnology (\#SC-394039). 


\section{Isolation of Cerebral Endothelial Cells From Adult Mouse Brains and Culture}

Primary CEC were isolated from adult 3-4 and 18-20 m/o old C57BL/6J mice using the Adult Brain Dissociation Kit according to the manufacturer's instructions (MACS Miltenyi Biotec, \#130107-677). Briefly, mouse brains were homogenized and enzymatically digested. Homogenized brains were filtered through $70 \mu \mathrm{m}$-pore strainers, and debris was separated by centrifugation $(3,000 \times g, 10 \mathrm{~m})$. Cellular suspensions were then treated to remove red blood cells. Finally, cellular suspension was plated in pre-coated flasks with $0.1 \%$ sterile porcine gelatin (Biological Industries, \#01-944-1B). Cells were maintained in Complete Mouse Endothelial Cell Medium/w Kit (Cell Biologics, \#M1168) supplemented with puromycin $(4 \mu \mathrm{g} /$ $\mathrm{ml}$ ) for $48 \mathrm{~h}$ to select endothelial cells (Perriere et al., 2005). After $48 \mathrm{~h}$, cells were washed with PBS to remove puromycin and debris. Cells were then maintained in fresh Complete Mouse Endothelial Cell Medium until 100\% confluence.

\section{Isolation of Cerebral Microvessels From Adult Mice}

Mouse brains were dissected and the cortices were homogenized in MCDB 131 medium (ThermoFisher, \#14190144) using a loose-fit 7-ml Dounce tissue grinder and centrifuged $(2,000 \times$ $g, 2 \mathrm{~m}$ ). After centrifugation, the pellets were resuspended in $15 \%$ $(w t / v o l)$ dextran-DPBS and centrifuged $(10,000 \times g, 15 \mathrm{~m})$ to remove white matter. The pellets were again resuspended with DPBS and filtered through $40 \mu \mathrm{m}$ strainer. Microvessels remained in the filter and were fixed with $4 \%$ paraformaldehyde-DPBS for $10 \mathrm{~m}$. The strainer was inverted and microvessels were collected in a $50 \mathrm{ml}$ tube with DPBS and centrifuged. The pellets were resuspended. $50 \mu \mathrm{l}$ of microvessels suspensions were placed on a microscope slide and air-dried overnight for subsequent immunostaining (Lee et al., 2019).

\section{Immunocytochemistry}

Cultured CEC were fixed with $4 \%$ paraformaldehyde for $10 \mathrm{~m}$, washed with PBS, and permeabilized with a $0.5 \%$ Triton-X100/ PBS solution for $10 \mathrm{~m}$ at room temperature. Fixed cells or microvessels were blocked with a solution containing 5\% bovine serum albumin and $0.1 \%$ Triton X-100 in PBS, at room temperature for $1 \mathrm{~h}$. Then, cells or microvessels were incubated with a solution of primary antibodies in blocking solution overnight at $4^{\circ} \mathrm{C}$. Cells or microvessels were washed and incubated with Alexa Fluor $^{\circledR}$-conjugated secondary antibodies against the host species used to generate the primary antibodies (Abcam), and with the Hoechst dye to stain nuclei, which was imaged in the DAPI channel.

A blinded investigator imaged 5-10 microscopic fields $(\times 20$ and $\times 40$ objectives) using the same exposure time and light intensity. We established threshold limits for each marker for quantitative analyses. The mean of fluorescence intensities in each region of interest was quantified with Image J software. The fluorescence intensities from the background of each picture were subtracted from the correspondent values of the region of interest in the same image.

\section{Western Blotting}

Cultured primary CEC were collected in RIPA buffer $(150 \mathrm{mM}$ $\mathrm{NaCl}, 1 \%$ Nonidet $\mathrm{P} 40,0.5 \%$ sodium deoxycholate, $0.1 \%$ SDS and $50 \mathrm{mM}$ Tris/ $\mathrm{HCl} \mathrm{pH} 8.0$ ), with a cocktail of phosphatase and protease inhibitors (Sigma Aldrich). Cells were lysed with three cycles of freezing-thawing. Each cycle consisted of $5 \mathrm{~m}$ in dry ice, $30 \mathrm{~s}$ in a water bath at $37^{\circ} \mathrm{C}, 5 \mathrm{~m}$ on ice, and vortex samples for $30 \mathrm{~s}$. Cellular lysates were cleared by centrifugation at $15,000 \times g$ for $15 \mathrm{~m}$ at $4^{\circ} \mathrm{C}$. The supernatants were collected and protein concentrations were analyzed by the PierceTM Bicinchoninic Acid Protein Assay Kit (ThermoFisher Scientific, \#23225). Cleared lysates were diluted in sample buffer, boiled at $95^{\circ} \mathrm{C}$ and run in $4-20 \%$ Mini-PROTEAN TGX gels (BioRad). Proteins were transferred on to nitrocellulose membranes in transfer buffer containing $20 \%$ methanol at $0.2 \AA$ for $2 \mathrm{~h}$ at $4^{\circ} \mathrm{C}$. Membranes were blocked with $5 \%$ non-fat dry milk ( $1 \mathrm{~h}$ at room temperature). Membranes were incubated with primary antibodies overnight at $4^{\circ} \mathrm{C}$. Then, membranes were incubated with secondary antibodies against the host species used to generate the primary antibodies conjugated with HRP $1 \mathrm{~h}$ at room temperature. Chemiluminescent signal was produced using SuperSignal $^{\mathrm{TM}}$ West Femto Maximum Sensitivity Substrate (ThermoFisher, \#34094) and detected with a charge-coupled device camera-based scanner.

The band intensity from each lane of the protein of interest was quantified with the ImageJ software and related to the band intensity of the correspondent lane of $\beta$-Tubulin.

\section{Senescence-Associated $\beta$-galactosidase Staining}

Cultured CEC were fixed with $4 \%$ paraformaldehyde at room temperature for $5 \mathrm{~m}$, washed with $\mathrm{PBS}$, and incubated with the $\beta$-galactosidase Staining Solution ( $1 \mathrm{mg} / \mathrm{ml} \mathrm{X-Gal,} \mathrm{pH}$ 6.0) from the Senescence $\beta$-galactosidase Staining Kit (Cell Signaling, $\# 9860$ ) at $37^{\circ} \mathrm{C}$, accordingly to the manufacturer's instructions. Fixed cells from all experiments were incubated for the same time $(24 \mathrm{~h})$ to avoid intensity changes due to differences in incubation times. The percentage of cells positive to the Senescence $\beta$-galactosidase Staining was calculated by a blinded investigator to experimental groups using ImageJ software.

\section{RNA G4 Detection Using Thioflavin T}

The oligonucleotides corresponding to the $3^{\prime}$-UTR of Ccn 1 mRNA and a negative control $(\mathrm{G}>\mathrm{T}$ in the putative $\mathrm{G} 4$ forming region) were dissolved in a buffer $(40 \mathrm{mM} \mathrm{KCl}$, $20 \mathrm{mM}$ tris- $\mathrm{HCl}, \mathrm{pH} 7.0$ ) for a $100 \mu \mathrm{M}$ stock solution. Thioflavin $\mathrm{T}$ was dissolved in hot water for a $100 \mu \mathrm{M}$ stock solution. The RNA stocks were dissolved in the buffer $(4 \mu \mathrm{M})$ and annealed by heating at $90^{\circ} \mathrm{C}$ for $2 \mathrm{~m}$ and then cooled down slowly to room temperature for $2 \mathrm{~h}$. The annealed RNA samples, or only the buffer as control, were mixed with Thioflavin $\mathrm{T}$ $(2 \mu \mathrm{M})$ in a 96-well plate and the fluorescence emission was measured at $484 \mathrm{~nm}$ with excitation at $440 \mathrm{~nm}$ in a microplate reader (Xu et al., 2016). The oligonucleotide sequences are:

3'-UTR Ccn1-G1: UCAUGGAGACGUGGGUGGGCGGAG GAUGAAU. 
3'-UTR Ccn1 -G1 Negative Control: UCAUGUAGACGU GGGUGGGCGGAGGAUGAAU.

\section{Gene Expression by RT-qPCR}

Cultured CEC were collected and processed following the manufacturer's instructions of the RNeasy Mini Kit (Qiagen, \#74104) to isolate total RNA. RNA was reverse transcribed with the iScript Reverse Transcription SuperMix (Bio-Rad, \#1708840) and then used to analyze the gene expression by qPCR. $2 \mu \mathrm{l}$ of cDNA of a sample were diluted in iTaq Universal SYBR ${ }^{\circledR}$ Green Supermix (BioRad, \#1725121) per reaction and run using a Bio-Rad CFX96 Touch device $\left(95^{\circ} \mathrm{C}\right.$ for $3 \mathrm{~m}$, and 40 cycles of $95^{\circ} \mathrm{C}$ for $10 \mathrm{~s}$ and $55^{\circ} \mathrm{C}$ for $\left.30 \mathrm{~s}\right)$.

Sequences of primers: Forward Mouse Con $15^{\prime}$-GTGAAGTGC GTCCTTGTGGACA-3'; Reverse Mouse Con1 $5^{\prime}$-CTTGACACT GGAGCATCCTGCA-3'; Forward Mouse Gapdh 5'-CAAGGT CATCCATGACAACTTTG-3'; Reverse Mouse Gapdh $5^{\prime}$-GTC CACCACCCTGTTGCTGTAG- ${ }^{\prime}$. The relative expression of the gene of interest was calculated with the double delta $\mathrm{Ct}$ method related to the relative expression of Gapdh.

\section{RNA Sequencing}

Cultured CEC isolated from young and aged male mice were cultured and maintained in $75 \mathrm{~cm}^{2}$ flask until cells reached $100 \%$ confluence. mRNA from each flask was isolated using the RNeasy Mini kit (Qiagen, \#74104) and reverse transcribed with the iScript cDNA Synthesis kit (Bio-Rad, \#1708890). cDNAs were sent to Qiagen for RNA sequencing analyses.

\section{Bioinformatics Analysis}

Putative G4 motifs in the Ccn1 mRNA were predicted using the G4Hunter bioinformatics tool (http://bioinformatics.ibp.cz/\#/) with the following settings: Threshold $=1.2$; Window size $=$ 25. A threshold of 1.2 provides a good estimation of potential G4 forming motifs with a false discovery rate (FDR) of $10 \%$. Window size of 25 is closed to the mean length of G4 forming sequences (26 nucleotides) (Bedrat et al., 2016). The G4Hunter analyses give a score for each analyzed sequence. A G4Hunter score of a sequence above 1 is regarded as a good predictor of its ability to fold into a G4 in vitro (Bedrat et al., 2016).

\section{Statistics}

All analyses were performed using GraphPad Prism software (v.7). We used Student's t-test to compare means from two independent groups. A value of $p<0.05$ was considered significantly different. Bar graphs represent mean \pm SEM.

\section{RESULTS}

\section{Cultured Primary CEC Isolated From the Brains of Aged Mice Show Senescence-Associated Phenotypes Compared With Young Mice}

We first evaluated the purity of our primary CEC culture preparation. Cultures of primary CEC from adult mice showed minimal contamination with other brain cell types
(Supplementary Figure S1). We compared the transcriptional signature of our CEC culture obtained from RNA sequencing analysis with that from the microvasculature of mice (Song et al., 2020 ), and found that $41 \%$ of the 1,000 highest upregulated genes found in cultured CEC from young males corresponded with the most upregulated genes found in the microvessels of 6-7 weeks old male mice (Supplementary Table S1). These genes are involved in important endothelial functions such as, transcription, translation, transport, cell-cell interaction, metabolism, proliferation, exocytosis and endocytosis, etc. Thus, our primary culture of CEC conserves important features of the brain vasculature and is relevant to studies of the cerebral endothelium.

We next generated primary CEC from the brains of 4 and 18$\mathrm{m} / \mathrm{o}$ mice to evaluate SA-phenotype. SA- $\beta$-galactosidase staining is commonly used as a marker of senescent cells as these cells exhibit enhanced activity of the lysosomal enzyme SA$\beta$-galactosidase (Dimri et al., 1995). Thus, CEC were stained for SA- $\beta$-galactosidase, and quantified as the percentage of cells positive to SA- $\beta$-galactosidase (Figures 1A,B). In addition, CEC from young or aged mice were stained with antibodies against $\gamma \mathrm{H} 2 \mathrm{AX}$ and $\mathrm{p} 16^{\mathrm{INK} 4 \mathrm{a}} \cdot \gamma \mathrm{H} 2 \mathrm{AX}$ is a marker of double-strand breaks, the most severe form of DNA damage (Noubissi et al., 2021); and $\mathrm{p} 16^{\mathrm{INK} 4 \mathrm{a}}$ is a tumor suppressor, overexpression of which is associated with cell cycle arrest and cell senescence (Oh et al., 2021). Aged CEC exhibited higher levels of both the DNA damage marker $\gamma \mathrm{H} 2 \mathrm{AX}$ (Figures 1C,D) and the tumor suppressor $\mathrm{p} 16^{\mathrm{INK4a}}$ (Figures 1E,F), compared with young cells. These findings indicate that the age-dependent senescent phenotype is recapitulated in the primary CEC, and that this experimental approach can be useful in the study of cerebral endothelial aging.

\section{Cultured CEC Isolated From Aged Mice Exhibit Higher Levels of G4}

G4 stabilization has been associated with aging (MorunoManchon et al., 2017; Lejault et al., 2020; Moruno-Manchon et al., 2020; Teng et al., 2020). Previously, we found that treating aged mice with pyridostatin (PDS) induced DNA damage, lipofuscin accumulation, and memory impairment in aged mice (Moruno-Manchon et al., 2020), indicating that the G4 structures play a causative role in SA phenotypes and aging.

In this experiment, we determined if cultured CEC isolated from aged mice exhibit enhanced levels of G4s. CEC from young and aged mice were stained with antibodies against G4s (BG4). We found that the BG4-positive puncta localized inside and outside the nuclei of aged CEC (Figures 2A,C). Anti-BG4 can recognize both DNA-G4 and RNA-G4. Thus, to evaluate predominantly RNA-G4, we incubated the fixed cells with DNaseI to deplete DNA targets $\left(1 \mathrm{mg} / \mathrm{ml}, 2 \mathrm{~h}, 37^{\circ} \mathrm{C}\right)$. We found that aged CEC still had higher levels of BG4, mostly located outside of the nuclei, compared with young CEC (Figures 2B,D). These results confirm that enhanced levels of DNA and RNA G4s are features of aging in cultured CEC. 


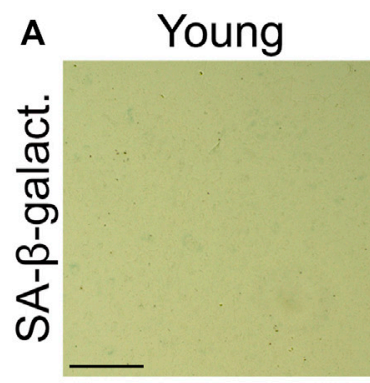

c Young

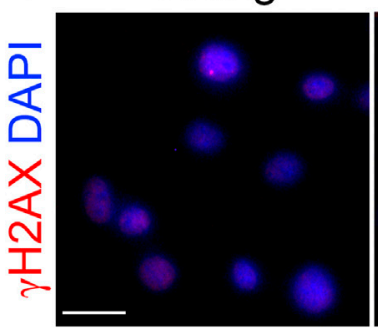

E

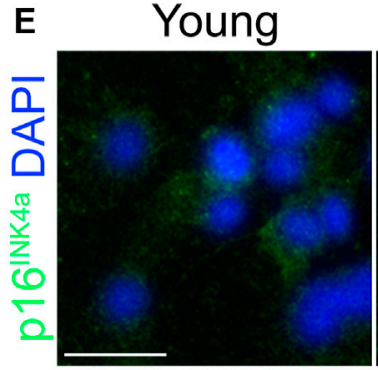

Aged

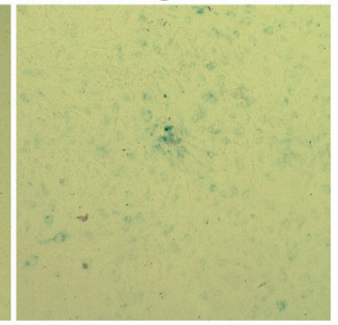

Aged

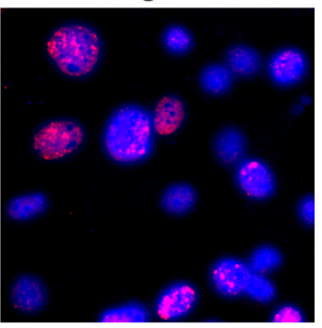

Aged

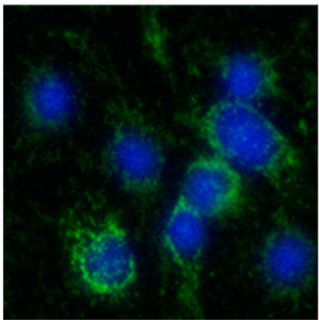

B

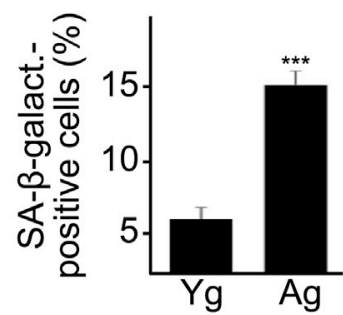

D

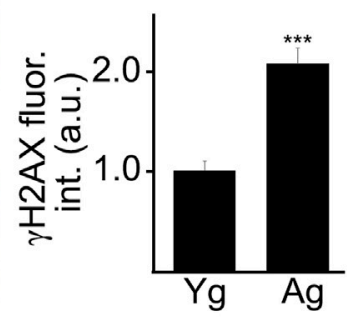

$\mathbf{F}$

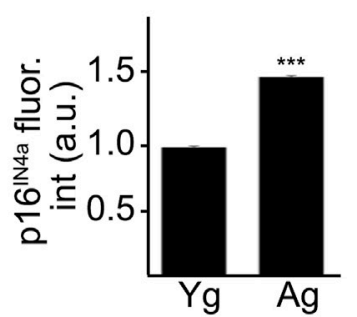

FIGURE 1 | Cultured primary CEC from aged mice recapitulated senescence-associated phenotypes observed in vivo. CEC were isolated from young (3-4 m/o) and aged (18-20 m/o) female mice and cultured. Young and aged cultured CEC were stained for SA- $\beta$-galactosidase (A), with antibodies against the double-strand DNA damage marker $\gamma \mathrm{H} 2 \mathrm{AX}(\mathbf{C})$, or with antibodies against the tumor suppressor p16 ${ }^{\mathrm{INK} 4 \mathrm{~A}}$ (E). The nuclear Hoechst dye was used to stain nuclei and imaged with the DAPI channel $(\mathbf{C}, \mathbf{E})$. The percentage of SA- $\beta$-galactosidase-positive cells (B), the fluorescence intensity of $\gamma \mathrm{H} 2 \mathrm{AX}(\mathbf{D})$ and the fluorescence intensity of $\mathrm{p} 16$ INK4A $(\mathbf{F})$ were quantified. Scale bar (A), $100 \mu \mathrm{m}$; scale bar (C), $25 \mu \mathrm{m}$; scale bar (E), $25 \mu \mathrm{m}$. $t$-test, ${ }^{\star \star *} p$-value $<0.0001$. Data were pooled from three independent experiments, 20 microscopic fields $(\mathbf{A}, \mathbf{B})$, or 50 cells $(\mathbf{C}-\mathbf{F})$ per each experiment and condition.

\section{G4 Stabilization Induces Senescence in Cultured CEC}

Next, we tested the hypothesis that G4 stabilization induces senescence in CEC. We can stabilize G4s in cultured cells by using small G4-stabilizing compounds, such as PDS that intercalate between guanines aligned in the G4 planar tetrads of a DNA or RNA sequence.

Given that cultured cells can become senescent days after a genotoxic stimulus (Kirkland and Tchkonia 2017), we treated CEC with a long-term exposure time of PDS at a low concentration. Cultured primary CEC isolated from aged mice were treated either with a low concentration of PDS $(0.5 \mu \mathrm{M})$, or a vehicle, for 4 days. Cells were fixed and stained with antibodies against $\gamma \mathrm{H} 2 \mathrm{AX}$, and we measured $\gamma \mathrm{H} 2 \mathrm{AX}$ fluorescence intensity. CEC treated with PDS showed higher $\gamma \mathrm{H} 2 \mathrm{AX}$ fluorescence intensity compared with control cells (Figures $\mathbf{3 A}, \mathbf{B}$ ). We also observed that CEC treated with PDS showed a significant increase in their nuclear size, which is also a feature of cell senescence (Rey et al., 2017; Bang et al., 2021) (Figure 3C). Another cohort of cultured primary CEC was treated either with PDS, or with a vehicle, and stained for SA- $\beta$-galactosidase. We found that a higher percentage of PDS-treated CEC was positive for SA$\beta$-galactosidase staining compared with the control cells (Figures 3D,E). Thus, G4 stabilization exacerbated senescence in cultured CEC isolated from aged mice.

\section{The Cerebral Vasculature and Cultured Primary CEC Isolated From Aged Mice Show Increased Levels of CCN1}

Enhanced levels of CCN1 have been associated with senescence in non-endothelial cell types (Jun and Lau 2010; Simmnacher et al., 2020). Thus, we hypothesized that CCN1 was upregulated in the cerebral vasculature of aged mice compared with young brains. We isolated cerebral microvessels from the brains of young and aged mice and stained with antibodies against an endothelial marker (CD31), and CCN1, and labeled nuclei with the Hoechst 

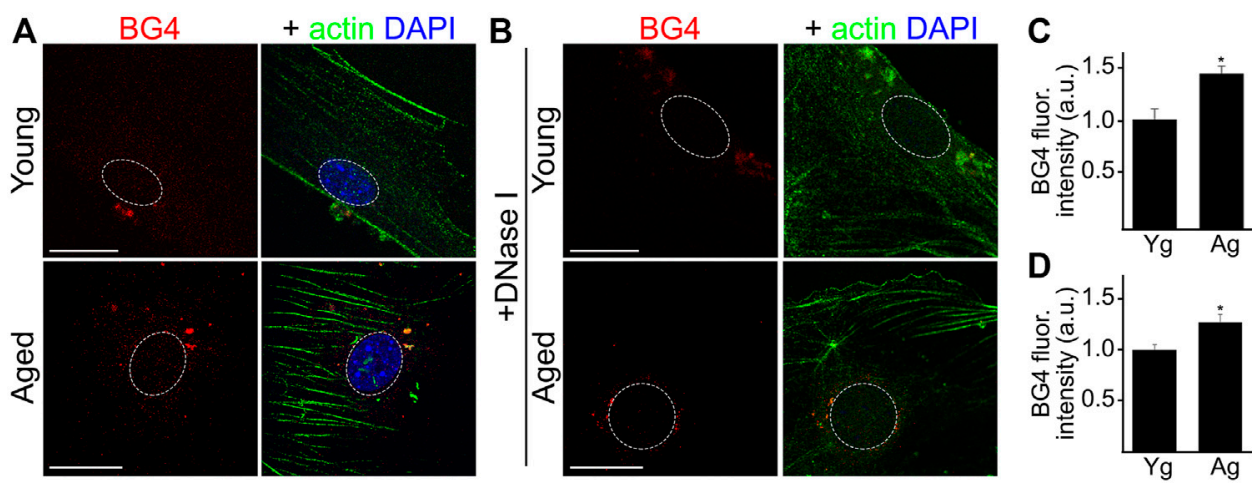

FIGURE 2 | Cultured CEC from aged mice showed higher levels of RNA-G4 than cultured young CEC. (A) CEC were isolated from young (4-m/o) and aged (20-m/ o) female mice and cultured. Cells were fixed and stained with antibodies against G4 (BG4) anti against actin, and with the nuclear Hoechst dye. (B) Cultured CEC from young and aged female mice were fixed and incubated with DNasel to eliminate DNA G4, and then stained with antibodies against G4 (BG4) and against actin, and with the nuclear Hoechst dye. (C,D) BG4 fluorescence intensities were measured. (C) Quantification from (A). Scale bar (Yg), $20 \mu m$; Scale bar (Ag), $40 \mu m . t$-test, ${ }^{*} p$-value $=0.0116$. (D) Quantification from (B). $t$-test, ${ }^{*} p$-value $=0.0435$. Data were pooled from three independent experiments analyzing 50 cells per condition and experiment.
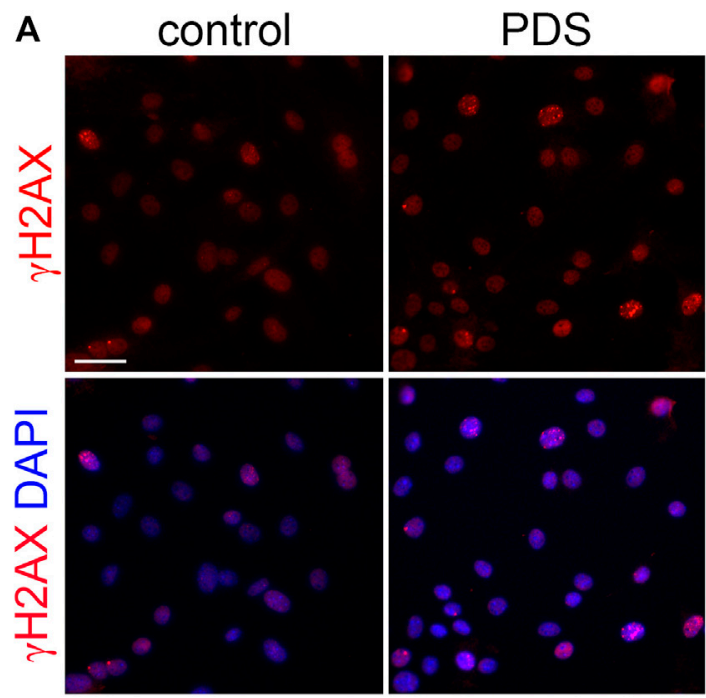

B

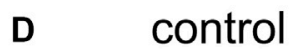

PDS
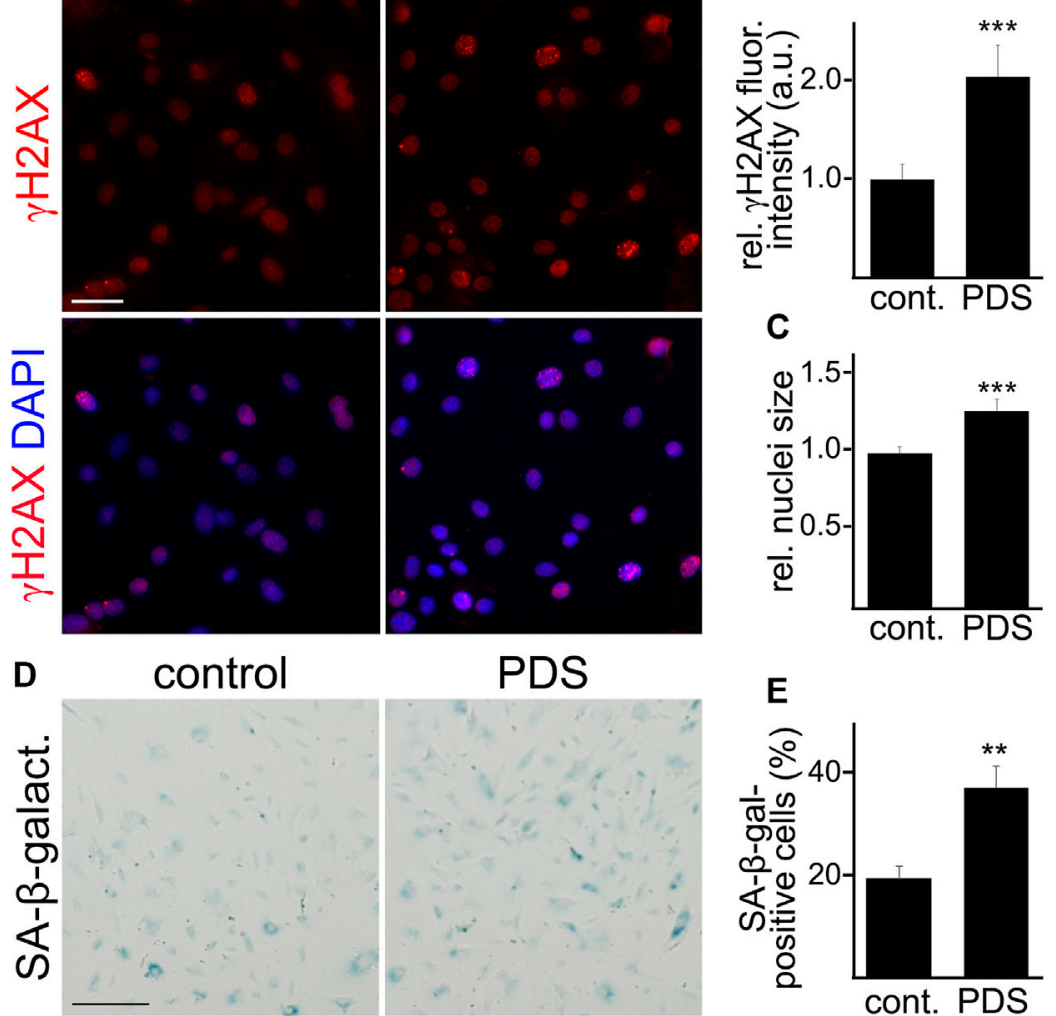

C
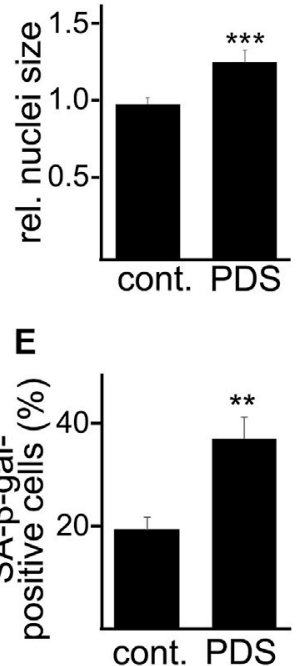

FIGURE 3 | A G4-stabilizing compound exacerbated senescence-associated phenotypes in cultured CEC. (A) CEC isolated from aged (18-20 m/o) female mice and cultured were treated with pyridostatin $(0.5 \mu \mathrm{M})$, or a vehicle (water), for 4 days. CEC were fixed and stained with antibodies against $\gamma \mathrm{H} 2 \mathrm{AX}$ and the nuclear $\mathrm{Hoechst}$ dye (DAPI channel). Scale bar, $50 \mu \mathrm{m}$ (B) Quantification of the fluorescence intensity of $\gamma \mathrm{H} 2 \mathrm{AX}$ from $(\mathbf{A})$. $t$-test, ${ }^{* \star \star} p$-value $=0.0003$. Data were pooled from three independent experiments analyzing 50 cells per condition and experiment. (C) Quantification of the nuclei size. $t$-test, ${ }^{\star \star \star} p$-value $=0.0001$. Data were pooled from three independent experiments analyzing 50 cells per condition and experiment. (D) CEC isolated from aged (18-20 m/o) female mice and cultured were treated with pyridostatin $(0.5 \mu \mathrm{M})$, or a vehicle (water), for 4 days. CEC were fixed and stained with the SA- $\beta$-galactosidase staining kit. Scale bar, $50 \mu \mathrm{m}$. (E) Quantification of the percentage of SA- $\beta$-galactosidase-positive cells. $t$-test, ${ }^{\star *} p$-value $=0.0015$. Data were pooled from three independent experiments analyzing 50 cells $(\mathbf{A}-\mathbf{C})$ or 20 microscopic fields (D,E) per condition and experiment. 

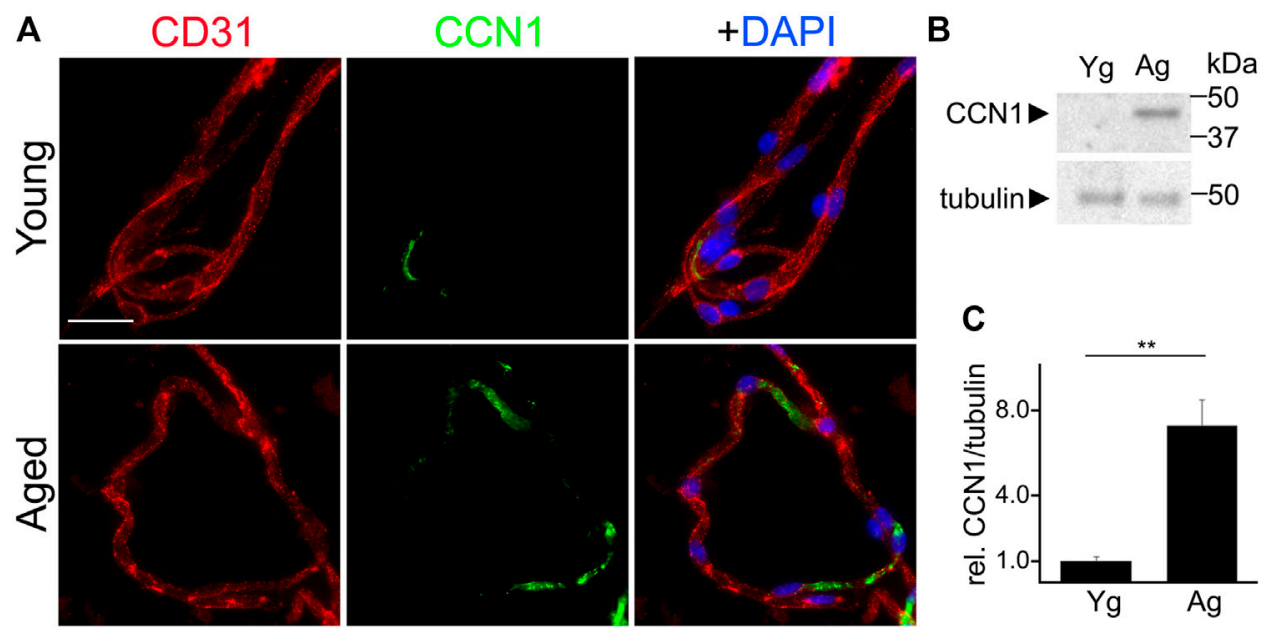

FIGURE 4 | CCN1 was upregulated in the microvessels isolated from the brains of aged mice and in cultured CEC isolated from aged mice compared with young mice. (A) Representative image of microvessels isolated from the brains of young (3-4 m/o) and aged (18-20 m/o) female mice, and stained with antibodies against the endothelial marker CD31, with antibodies against CCN1, and with the nuclear Hoechst dye (DAPI channel). Scale bar, $25 \mu \mathrm{m}$. (B) CEC were isolated from young (3-4- m/ o) and aged (18-20 m/o) female mice, cultured and maintained until 100\% confluence. Cells were collected and lysed and processed for gel electrophoresis and analyzed for Western blotting. (C) Band intensities of CCN1 relative to tubulin. $t$-test, ${ }^{\star \star} p$-value $<0.0019$. Data were obtained from four mice per age.

dye. We found that the fluorescence intensity of CCN1 was enhanced in the cerebral microvessels from aged mice compared with young mice (Figure 4A). Similarly, we determined whether cultured primary $\mathrm{CEC}$ also recapitulate the enhancement of CCN1 levels with aging as we observed in microvessels from aged mice. Thus, we generated primary CEC from young and aged mice and measured CCN1 levels by Western blotting. The level of CCN1 was significantly increased in CEC from aged mice compared with young mice (Figures 4B,C).

Our data indicate that microvessels and CEC isolated from the brains of aged mice show enhanced SA phenotype compared with those from young mice, and that CCN1 was upregulated in the cerebrovasculature and in cultured primary CEC with aging. These findings suggest that senescence in the cerebral vasculature is associated with enhanced levels of CCN1 in aged mice. However, whether increased CCN1 is a causative factor in promoting senescence in primary CEC remained to be established.

\section{CCN1 Enhances Senescence Phenotype in Cultured CEC From Aged Mice}

CCN1 induces senescence in cultured human fibroblasts (Jun and Lau 2010), and Ccn1 is the most upregulated gene in cultured human fetal astrocytes treated with $\mathrm{H}_{2} \mathrm{O}_{2}$, which is commonly used to induce senescence (Simmnacher et al., 2020). However, Ccn 1 is not significantly upregulated in reactive astrocytes (Simmnacher et al., 2020). This highlights the specific relevance of $\mathrm{CCN} 1$ to cell senescence. We propose that increased CCN1 promotes senescence in CEC. To test, CEC were isolated from the brains of aged mice and cultured. Cultured CEC were then treated either with recombinant $\mathrm{CCN} 1(2.5 \mu \mathrm{M})$ or vehicle for 4 days and then stained for SA- $\beta$-galactosidase. We observed a higher percentage of SA- $\beta$-galactosidase positive cells in the CCN1 treated group (Figures 5A,B). Similarly, we observed that CEC treated with $\mathrm{CCN} 1$ had significantly higher fluorescence intensities of $\gamma \mathrm{H} 2 \mathrm{AX}$ (Figures 5C,D). This indicates that CCN1 can enhance the SA phenotype in aged CEC. Moreover, cultured CEC treated with CCN1 or a vehicle for 4 days were also stained with antibodies against CCN1. We observed that CCN1-treated cells had 4-fold increase of CCN1 levels compared with control cells (Figures 5E,F), suggesting that $\mathrm{CCN} 1$ could promote the synthesis of $\mathrm{CCN} 1$ in a positive feedback mechanism. This effect may be relevant to the propagation of SA-phenotype to other cells.

\section{CCN1 Levels Are Upregulated by G4 Stabilization in Cultured CEC}

$C c n 1$ is transcriptionally activated immediately after exposure to multiple stimuli, such as growth factors (O'Brien et al., 1990; Brunner et al., 1991; Cui et al., 2011), hormones (Hilfiker et al., 2002; Hilfiker-Kleiner et al., 2004), different stressors (including hypoxia (Kunz et al., 2003), UV light (Quan et al., 2006), and mechanical stretch (Chaqour and Goppelt-Struebe 2006; Kivela et al., 2007)), and microorganisms (Kim et al., 2004; Kurozumi et al., 2008; Wiedmaier et al., 2008). However, it is unknown how physiological aging can upregulate CCN1.

A study found that the expression of CCN1 in human cancer cells could be upregulated via the stabilization of G4s in the $3^{\prime}$ UTR of the human CCN1 mRNA near the stop codon (Sanders et al., 2013). DNA and RNA with guanine sequences intercalated between other bases can fold into G4 structures. Increased G4s have been associated with aging (Lejault et al., 2020; MorunoManchon et al., 2020; Teng et al., 2020). Whether CCN1 can be upregulated by G4 stabilization in cultured mouse CEC has not 

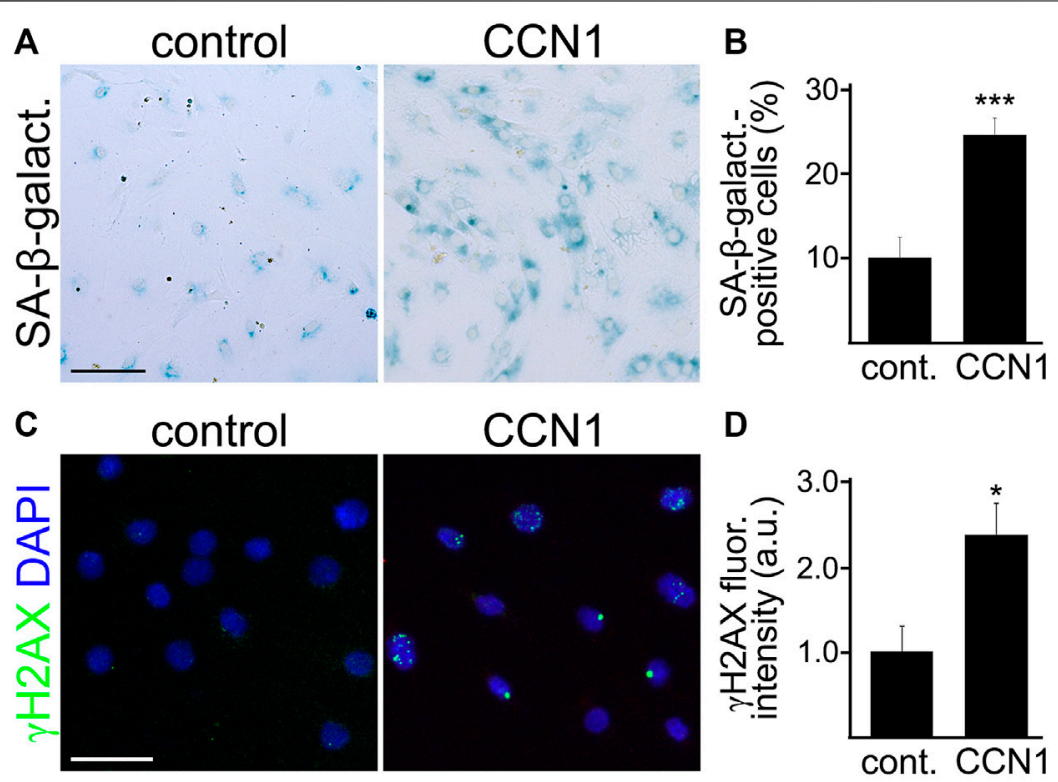

D
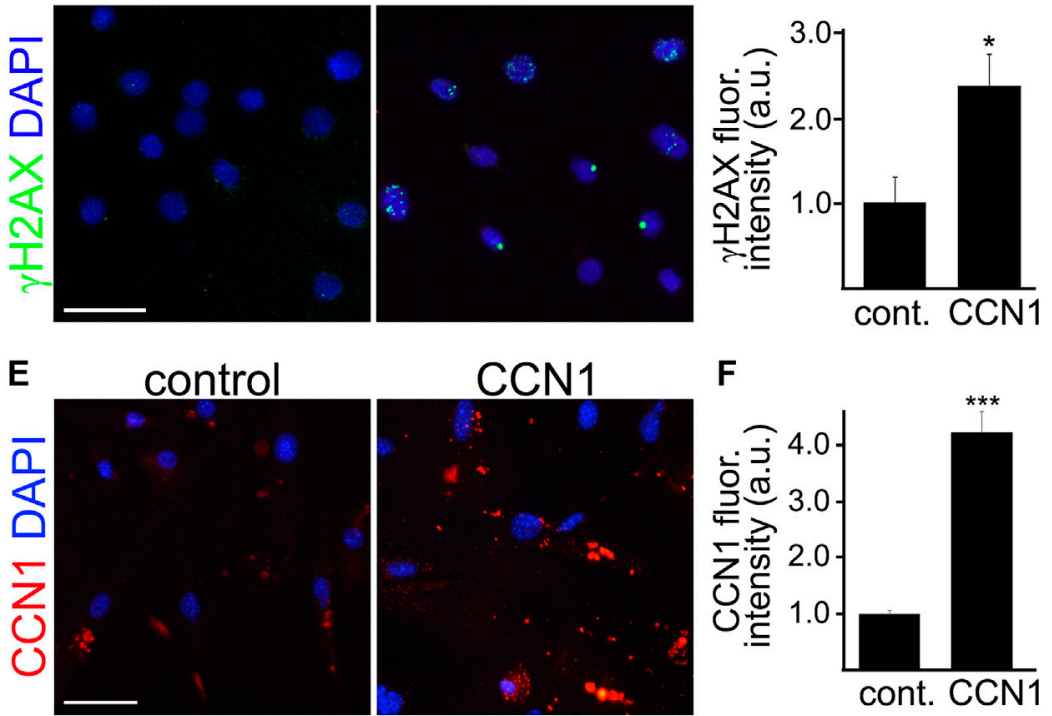

FIGURE 5 | CCN1 induced senescence-associated phenotypes in cultured CEC. CEC were isolated from aged (18-20 m/o) female mice and cultured. Cultured CEC were stained with SA- $\beta$-galactosidase staining kit (A), or with antibodies against the double-strand DNA damage marker $\gamma \mathrm{H} 2 \mathrm{AX}$ (C), or with antibodies against CCN1 (E), and with the nuclear Hoechst dye (C,E). The percentage of SA- $\beta$-galactosidase-positive cells (B), the fluorescence intensity of $\gamma \mathrm{H} 2 \mathrm{AX}(\mathbf{D})$, and the fluorescence intensity of CCN1 (F) were quantified. Scale bar (A), $100 \mu \mathrm{m}$; scale bar (C), $50 \mu \mathrm{m}$; scale bar (E), $50 \mu \mathrm{m}$. $t$-test, ${ }^{* \star *} p$-value (B) = $0.0001, n=4$; ${ }^{\star} p$-value (D) $=0.0164,{ }^{\star \star \star} p$-value $\mathbf{( F )}=0.0001$. Data were pooled from three independent experiments analyzing 20 microscopic fields (A,B,E,F) or 50 cells (C,D) per condition and experiment.

been demonstrated. Thus, we tested the hypothesis that the $3^{\prime}$ UTR of the mouse Ccn 1 mRNA also folds into a G4.

Using the bioinformatics tool G4Hunter, we found that the mouse Ccn 1 mRNA has three putative G4 motifs in the $3^{\prime}$-UTR and none in the $5^{\prime}$-UTR (Figure 6A). Two of these putative G4s in the $3^{\prime}$-UTR in the mouse Ccn 1 mRNA have a high G4Hunter score (1.148), suggesting that these sequences have the ability to fold into G4s. The sequence located 51 nucleotides after the stop codon ( $3^{\prime}$-UTR Ccn1-G1) shares $100 \%$ homology with the G4 motif found in the $3^{\prime}$-UTR in the CCN1 mRNA of humans. To confirm that the G4 sequence in the $3^{\prime}$-UTR of the Ccn 1 mRNA of mice can indeed fold into a G4, we measured the fluorescence intensity of Thioflavin T (ThT) in combination with an oligo containing the $3^{\prime}$-UTR in Ccn 1 mRNA, or with an oligo with a single modification in a nucleotide from the original $3^{\prime}$-UTR $C c n 1$ sequence, which we used as a negative control as it is not predicted to fold into a G4. While ThT can bind to DNA G4 structures (Zhang et al., 2018), it can also bind to other non-G4 DNA forms (Xu et al., 2016). However, when ThT interacts with
RNA G4 it causes an enhancement in the fluorescence intensity of the formed complex by several hundred-fold (Renaud de la Faverie et al., 2014; Xu et al., 2016). This increase in fluorescence intensity of ThT does not occur when ThT is incubated with other RNA forms (Xu et al., 2016). Thus, measuring the fluorescence intensity of ThT in combination with a putative RNA G4 sequence is a quick and feasible method to quantify the ability of an oligo to fold into a G4. We observed that the fluorescence intensity of ThT was enhanced by several thousand times when incubated with the $3^{\prime}$-UTR Ccn 1 oligo, compared with the fluorescence of ThT alone or with the fluorescence of the oligonucleotide alone (Figure 6B). We also observed that modifying one single nucleotide in this sequence resulted in a significant reduction of fluorescence intensity. This finding suggests the potential for the $3^{\prime}$-UTR of Ccn 1 RNA to fold into a G4 structure.

Opposite to the G4 stabilization in $5^{\prime}$-UTR motifs, the formation of G4s in $3^{\prime}$-UTR has been associated with enhanced translation (Pelletier and Sonenberg 1985; Koromilas 

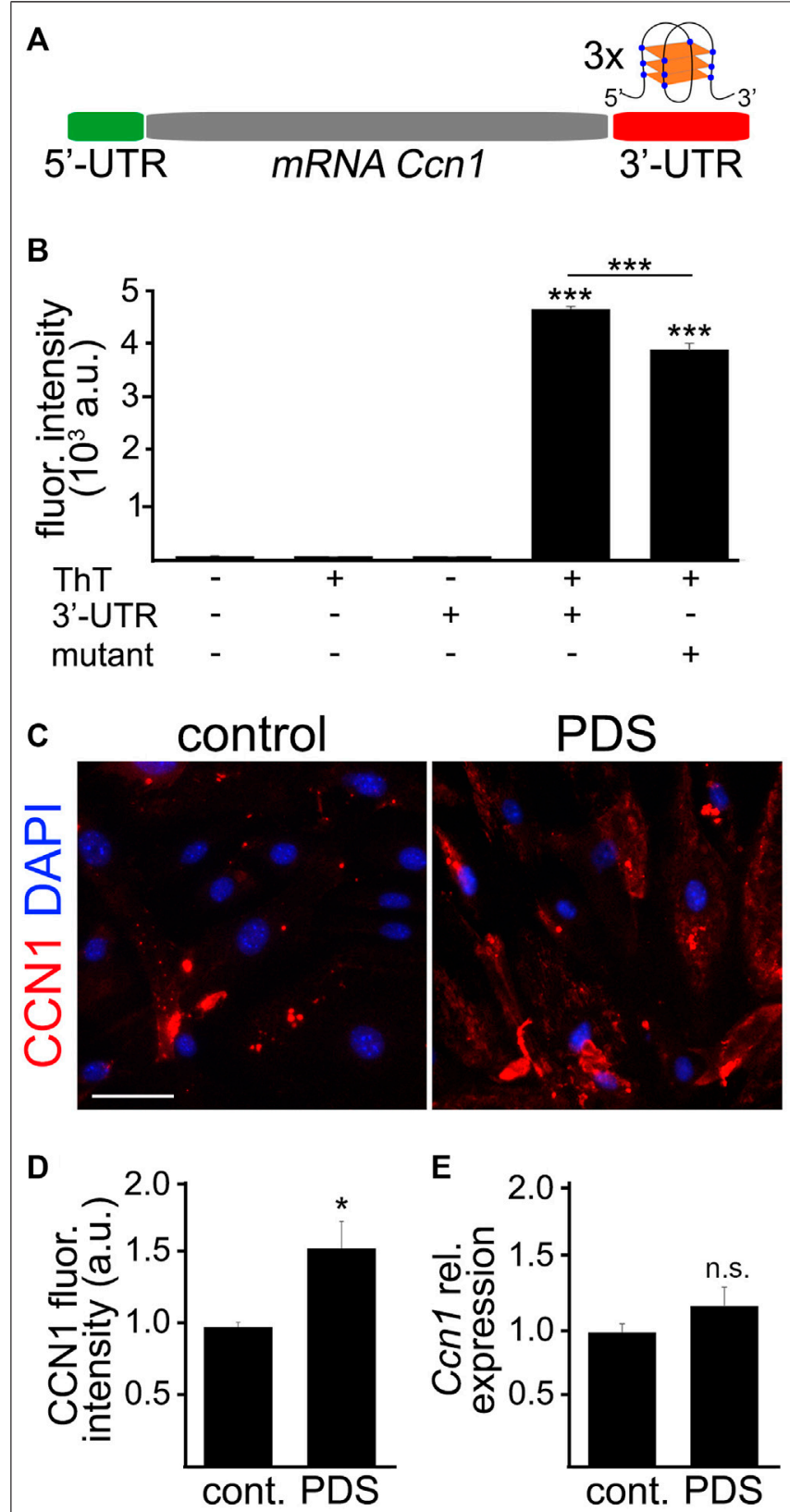

FIGURE 6| The $3^{\prime}$-UTR Ccn1 mRNA folded into G4s. (A) Scheme of the mRNA Ccn1 where the 5'-UTR (green) does not contain any potential G4 motif, and the $3^{\prime}$-UTR (red) contains three potential G4 motifs. In the representation of a RNA G4 structure, blue dots indicate Gs and orange rectangles indicate planar rearrangements between Gs. (B) The RNA sequence containing the potential G4 in the $3^{\prime}$-UTR Ccn1 near the stop codon ( $3^{\prime}$-UTR) or the RNA sequence containing the $3^{\prime}$-UTR Ccn 1 with a single mutation (mutant), as a negative control, were incubated at $90^{\circ} \mathrm{C}$ for $2 \mathrm{~m}$, and cooled down at room temperature for $2 \mathrm{~h}$. Then, the annealed RNA $3^{\prime}-U T R$ and mutant sequences were mixed with a Thioflavin T (ThT) solution, and the fluorescence emission was measured. As controls we used the buffer alone, a ThT solution alone, and the $3^{\prime}$-UTR sequence alone. One-way ANOVA, ${ }^{\star \star \star} p$-value $<0.0001$. Data were collected from four independent experiments. (C) CEC isolated from aged (18-20 m/o) female mice and cultured were treated with pyridostatin $(0.5 \mu \mathrm{M})$, or a vehicle (water), for 4 days. CEC were fixed and stained with antibodies against CCN1 and with the nuclear Hoechst (Continued)
FIGURE 6 | dye (DAPI channel). Scale bar, $50 \mu \mathrm{m}$. (D) Quantification of the fluorescence intensity of CCN1 from (C). $t$-test, ${ }^{*} p$-value $=0.0103$. Data were pooled from three independent experiments analyzing 20 microscopic fields per condition and experiment. (E) CEC isolated from aged (18-20 m/o) female mice and cultured were treated with pyridostatin $(0.5 \mu \mathrm{M})$, or a vehicle, for 4 days. RNA was isolated and GPCR was performed for the relative expression of Ccn1. We used Gapdh as a housekeeping gene. t-test, n.s., nonsignificant, $p$-value $=0.2424$. Data were pooled from four independent experiments.

et al., 1992). Given that the $5^{\prime}$-UTR in Ccn1 mRNA does not contain any putative G4, we hypothesized that the presence of putative G4s in the $3^{\prime}$-UTR in Ccn 1 mRNA can promote the upregulation of CCN1 in cultured CEC. By using the G4stabilizing compound PDS we can stabilize G4s in cultured cells. Using this approach, we aimed to determine whether CCN1 is upregulated by G4 stabilization in CEC. Thus, cultured primary CEC isolated from aged mice were treated either with PDS $(0.5 \mu \mathrm{M})$, or with a vehicle, for 4 days. Cells were stained with antibodies against CCN1 and with the nuclear Hoechst dye. We observed that the CCN1 levels were significantly increased in CEC treated with PDS compared with vehicletreated cells (Figures 6C,D). To determine if PDS affects the expression of $C c n 1$, CEC were incubated with PDS as mentioned and their RNA was collected for qPCR analyses. We found that the relative expression of $C c n 1$ in CEC treated with PDS was not significantly different compared with control cells (Figure 6E). This suggests that G4 stabilization regulates $\mathrm{CCN} 1$ more importantly at the translational levels than at the transcriptional levels.

\section{DISCUSSION}

Our study indicates that enhanced stabilization of G4s was associated with enhanced SA phenotype in CEC isolated from aged mice. We found that the extracellular component $\mathrm{CCN} 1$ was upregulated in the brain microvasculature of aged mice and in cultured CEC from aged mice, compared with young mice. Furthermore, CCN1 was upregulated by G4 stabilization in cultured CEC, likely at the translational level. Thus, our data suggest that the stabilization of RNA-G4s in aging could be an underlying mechanism of cerebrovascular senescence.

Around $10 \%$ of CEC have been found to undergo senescence in the brain of aged mice (28-m/o) (Kiss et al., 2020). Senescence of CEC can contribute to cerebrovasculature impairment in a multifaceted manner: dysregulating cerebral blood flow, increasing $\mathrm{BBB}$ permeability and changing the cerebrovasculature architecture (Del Valle et al., 2009; Yang et al., 2017; Graves and Baker 2020; Schumacher et al., 2021). Senescence in the brain has been associated with cerebral hypoperfusion (Pincon et al., 2019) and dementia (Zhang et al., 2013; Wang et al., 2018). Alarmingly, the number of individuals affected by dementia, mainly in people after age 65 (Seetlani et al., 2016), is expected to increase to 70 million by 2030 (Wolters and Ikram 2019). Thus, with the increasing number of people living to very advanced ages, the significance of our study 
is further strengthened. The possibility of modulating the synthesis of senescence-inducing factors, such as CCN1, could potentially prevent or mitigate senescence in the brain vasculature.

The role of CCN1 in senescence has been documented in studies using human fibroblasts (Jun and Lau 2010). CCN1 binds to integrin $\alpha_{6} \beta_{1}$ and heparin sulfate proteoglycans and activates the DNA damage response factors ATM, CHK1, CHK2 and p53. In a reactive oxygen species-dependent manner, the signaling pathways p38 MAPK and ERK are also stimulated by CCN1, and this triggers the $\mathrm{p} 16^{\mathrm{INK} 4 \mathrm{a}} / \mathrm{pRb}$ pathway, which promotes cellular senescence. CCN1 also induces the expression of matrix metalloproteinases that are part of the SASP. Cells that bind to extracellular CCN1 exhibit higher ROS levels compared with cells adhered to other extracellular matrix components, such as collagen, fibronectin, or laminin. Similar to CCN1, laminin binds to $\alpha_{6} \beta_{1}$ and heparin sulfate proteoglycans; however, it does not induce senescence, like CCN1 does (Jun and Lau 2010). This suggests that senescence induction is a particular feature of CCN1 among other extracellular matrix components, and that CCN1 may act via other receptors in addition to $\alpha_{6} \beta_{1}$ and heparin sulfate proteoglycans. Elucidating the $\mathrm{CCN} 1$-associated signaling pathways could help to develop therapeutic strategies to mitigate endothelial senescence.

Over 13,000 loci form RNA-G4 within the human transcriptome in vitro. Around 3,700 potential RNA-G4s were found in 2,500 genes (Kwok et al., 2016), mostly located in the $5^{\prime}$ and $3^{\prime}$-UTRs of mRNA (Song et al., 2016; Fay et al., 2017). High number of RNA-G4s in the $5^{\prime}$-UTRs interrupt mRNA translation (Pelletier and Sonenberg 1985; Koromilas et al., 1992). However, RNA-G4s in $3^{\prime}$-UTRs can positively regulate translation, where the polyA tail binds to elongation factors, which results in mRNA circulation and enhanced initiation rate (Sonenberg and Hinnebusch 2009). We found that the $5^{\prime}$-UTR in Ccn 1 mRNA does not contain G-rich motifs with the potential ability to fold into G4s. However, its $3^{\prime}$-UTR has three putative G4s and we observed that the closest sequence to the stop codon can fold into RNA-G4 using ThT. This may explain why CCN1 levels were upregulated in cultured CEC treated with the G4-stabilizing molecule PDS. Strikingly, a study found that the $3^{\prime}$-UTR plays a repressive role in the human CCN1 expression (Nakagawa et al., 2013). The authors found that the proximal half of the $3^{\prime}$-UTR, mainly between the downstream 50 and 160 bases, negatively interferes with the post-transcriptional regulation of CCN1. However, the region with the first 160 bases contains the G4forming sequence that folds into RNA-G4 (Sanders et al., 2013). The experiments in the Nakagawa study were performed under G4 non-inducing conditions. This suggests that the proximal half of the $3^{\prime}$-UTR may repress CCN1 expression under normal conditions; however, with G4 stabilizers, the $3^{\prime}$-UTR may fold into a G4, and the role of G4s in the $3^{\prime}$-UTR on the posttranscriptional activity in CCN1 is inverted and thus could promote CCN1 upregulation. G4 ligands with high affinity to RNA-G4 prevent cell proliferation by promoting cell cycle exit (Goldberg et al., 2020), suggesting that the stabilization of RNAG4s causes cell senescence. Further studies are needed to determine if modifications of nucleotides in the RNA-G4 forming sequence in the $3^{\prime}$-UTR $C c n 1$ mRNA could prevent $\mathrm{CCN} 1$ upregulation under conditions where G4 stabilization occurs, such as aging.

The role of the G4 stabilization on cell senescence has been investigated in the cancer field. Small G4-stabilizing compounds induce senescence in cancer cells (Riou et al., 2002; Huang et al., 2012), which makes these compounds potential candidates for anticancer therapy. It is generally accepted that a common mechanism of these G4-stabilizers is acceleration of telomere shortening, which is an important feature of aging. However, as G4 stabilization regulates multiple cellular processes (transcription (Armas et al., 2017; Moruno-Manchon et al., 2020), translation (Schaeffer et al., 2001; Khateb et al., 2007), RNA splicing (Zhang et al., 2019), mRNA subcellular localization (Subramanian et al., 2011), and DNA integrity (MorunoManchon et al., 2017; Techer et al., 2017)), mechanisms besides telomere shortening may also be involved in cell senescence. For example, DNA damage is the primary cause of senescence and aging (Schumacher et al., 2021). Relevant to the brain, we previously demonstrated that the stabilization of G4s induces DNA damage in cultured primary neurons (MorunoManchon et al., 2017; Tabor et al., 2021), and in cultured primary astrocytes and microglia (Tabor et al., 2021). Subventricular zone neural stem and progenitor cells treated with PDS also showed enhanced DNA damage (Goldberg et al., 2020). Autophagy is another process that has been implicated in cell senescence (Rajendran et al., 2019). Autophagy is a self-digesting mechanism that maintains cellular functions and survival. Stimulating autophagy can prevent senescence in vascular smooth muscle cells (Li et al., 2014; Luo et al., 2017). We demonstrated that inducing G4 stabilization inhibited autophagy in cultured neurons (Moruno-Manchon et al., 2020) and astrocytes (Lejault et al., 2020). Furthermore, we demonstrated that aged mice treated with PDS showed enhanced SA phenotype in their brains, such as increased lipofuscin accumulation and DNA damage. These mice also exhibited enhanced memory deficits compared with control aged mice (Moruno-Manchon et al., 2020). Thus, these studies highlight the influence of G4 stability in cell senescence in the brain and cognitive function.

While overall protein synthesis is decreased in senescent cells (Makrides 1983), the levels of mRNAs encoding SASP factors are enhanced with senescence (Coppe et al., 2008). We show evidence that stabilizing G4s can upregulate the senescence-inducing component CCN1 in cultured endothelial cells. Other labs have demonstrated that upregulating $\mathrm{CCN}$ members promote senescence and SASP in other cell types (Jun and Lau 2017; Feng et al., 2020), and that downregulating CCN1 reduced the expression of SASP factors (Feng et al., 2020). From this evidence, we hypothesize that other SASP could be regulated by G4s. Indeed, the expression of the SASP component vascular endothelial growth factor (VEGF) is downregulated by G4 stabilization. The Hurley lab was the first to demonstrate that the promoter region of VEGF naturally folds into G4s (Sun et al., 2005; Guo et al., 2008; Sun et al., 2008). Since then, investigators have been developing aptamers to target G4-forming sequences in VEGF promoter as a therapeutic application in cancer. 
Aptamers are short DNA or RNA sequences that specifically recognize molecules with high affinity. Anti-VEGF DNA-based aptamers forming G4s have been synthesized to visualize and target VEGF (Riccardi et al., 2021). The use of aptamers shows less toxicity and reduced immunogenicity over antibodies, and they are easy to produce. Thus, the development of G4 motifbased aptamers is feasible and has an important therapeutic potential (Duchler 2012) including for preventing or possibly reversing senescence. For example, aptamers have been used in animal models to rejuvenate bone tissue (Aldahmash 2016). We therefore propose that an important strategy could involve identifying G4 motifs is SASP components and that developing G4 motif-based molecules to target these senescence-inducing factors could reverse or prevent senescence in the cerebral endothelium.

A limitation in our study is that our experiments were performed using CEC isolated from only female mice. Studying the effects of $\mathrm{CCN} 1$ on senescence in aged female mice is relevant to vascular aging in women. The arteries of postmenopausal women are stiffer than the arteries of age-matched men (Merz and Cheng 2016). Arterial stiffness is associated with increased blood pressure and it is a risk factor for cardiovascular events (Bonarjee 2018). Elderly women have higher rates of hypertension than men (Merz and Cheng 2016). Physiological levels of CCN1 are required for optimal vascular stiffness, as CCN1 loss leads to alterations of vessel structure and integrity (Lee et al., 2019). However, high levels of CCN1 have been associated with pathological vascular stiffness (Reid et al., 2017; Chaqour 2020). Whether sex differences exist in the expression and translation of Ccn1, the contributions of gonadal hormones and sex chromosomes (XX vs XY), and their implication in the cerebrovasculature is being actively pursued in our lab.

In conclusion, our study supports a model in which the stabilization of G4s in aging contributes to brain vasculature senescence by regulating the levels of SASP factors such as CCN1. Therefore, developing G4 motif-based molecules to target these senescence-inducing factors should be explored as an approach to reverse or mitigate senescence in the cerebrovasculature.

\section{DATA AVAILABILITY STATEMENT}

The RNAseq data presented in this study can be found in online repositories. The names of the repository/repositories and accession number(s) can be found below: https://www.ncbi. nlm.nih.gov/bioproject/785238.

\section{REFERENCES}

Agarwal, T., Roy, S., Kumar, S., Chakraborty, T. K., and Maiti, S. (2014). In the Sense of Transcription Regulation by G-Quadruplexes: Asymmetric Effects in Sense and Antisense Strands. Biochemistry 53 (23), 3711-3718. doi:10.1021/bi401451q

Aldahmash, A. (2016). Skeletal Stem Cells and Their Contribution to Skeletal Fragility: Senescence and Rejuvenation. Biogerontology 17 (2), 297-304. doi:10.1007/s10522-015-9623-7

Armas, P., David, A., and Calcaterra, N. B. (2017). Transcriptional Control by G-Quadruplexes: In Vivo Roles and Perspectives for Specific Intervention. Transcription 8 (1), 21-25. doi:10.1080/21541264.2016.1243505

\section{ETHICS STATEMENT}

The animal study was reviewed and approved by Center for Laboratory Medicine and Care at the University of Texas McGovern Medical School.

\section{AUTHOR CONTRIBUTIONS}

BN isolated cerebral microvessels, cultured CEC, treated cells with drugs, performed western blots and imaged cells; MBC performed immunocytochemistry and imaged microvessels; YJL performed RNA sequencing; BG, AU, IMG, SPM, and LDM were advisors for the study and edited the manuscript; JFMM performed Thioflavin T experiments, analyzed data, wrote the manuscript, and designed the study.

\section{FUNDING}

This work was supported by American Heart Association (\#865061 to JFMM), by the U.S. Department of Defense (\#W81XWH-17-1-0632 to IMG), by the Spanish Ministry of Science and Innovation (\#PID2019-107090RA-I00 to IMG), by the Ramon y Cajal Program (\#RYC-2017-21879), by the University of Malaga and FEDER awards (\#UMA20FEDERJA-104 and \#B1-2019_06 to IMG), by National Institute of Health (NIH)/NINDS (\#NS114768 to PGB), by NIH/NIA (\#AG070934 to PGB), by the NIH/NIA (\#AG057576 to AU), by the NIH (\#NS120709 to SPM), and the NIH/NINDS (\#NS094543 and NS103592 to LDM).

\section{ACKNOWLEDGMENTS}

We thank Lori Capozzi and Cheryl Hayes for administrative assistance.

\section{SUPPLEMENTARY MATERIAL}

The Supplementary Material for this article can be found online at: https://www.frontiersin.org/articles/10.3389/fragi.2021.797562/ full\#supplementary-material

Bang, M., Gonzales, E. L., Shin, C. Y., and Kwon, K. J. (2021). Late Passage Cultivation Induces Aged Astrocyte Phenotypes in Rat Primary Cultured Cells. Biomolecules Ther. 29 (2), 144-153. doi:10.4062/biomolther.2020.175

Bedrat, A., Lacroix, L., and Mergny, J.-L. (2016). Re-evaluation of G-Quadruplex Propensity with G4Hunter. Nucleic Acids Res. 44 (4), 1746-1759. doi:10.1093/ nar/gkw006

Bonarjee, V. V. S. (2018). Arterial Stiffness: A Prognostic Marker in Coronary Heart Disease. Available Methods and Clinical Application. Front. Cardiovasc. Med. 5, 64. doi:10.3389/fcrm.2018.00064

Brunner, A., Chinn, J., Neubauer, M., and Purchio, A. F. (1991). Identification of a Gene Family Regulated by Transforming Growth Factor- $\beta$. DNA Cel Biol. 10 (4), 293-300. doi:10.1089/dna.1991.10.293 
Castillo Bosch, P., Segura-Bayona, S., Koole, W., Heteren, J. T., Dewar, J. M., Tijsterman, M., et al. (2014). FANCJ Promotes DNA Synthesis Through Gquadruplex Structures. EMBO J. 33 (21), 2521-2533. doi:10.15252/ embj. 201488663

Chaqour, B. (2020). Caught Between a "Rho" and a Hard Place: Are CCN1/CYR61 and CCN2/CTGF the Arbiters of Microvascular Stiffness? J. Cel Commun. Signal. 14 (1), 21-29. doi:10.1007/s12079-019-00529-3

Chaqour, B., and Goppelt-Struebe, M. (2006). Mechanical Regulation of the Cyr61/ CCN1 and CTGF/CCN2 Proteins. FEBS J. 273 (16), 3639-3649. doi:10.1111/ j.1742-4658.2006.05360.x

Chen, Y., and Liu, L. (2012). Modern Methods for Delivery of Drugs Across the Blood-Brain Barrier. Adv. Drug Deliv. Rev. 64 (7), 640-665. doi:10.1016/ j.addr.2011.11.010

Coppé, J. P., Patil, C. K., Rodier, F., Sun, Y., Muñoz, D. P., Goldstein, J., et al. (2008). Senescence-associated Secretory Phenotypes Reveal Cell-Nonautonomous Functions of Oncogenic RAS and the P53 Tumor Suppressor. Plos Biol. 6 (12), 2853-2868. doi:10.1371/journal.pbio.0060301

Cui, T. X., Lin, G., LaPensee, C. R., Calinescu, A.-A., Rathore, M., Streeter, C., et al. (2011). C/EBP $\beta$ Mediates Growth Hormone-Regulated Expression of Multiple Target Genes. Mol. Endocrinol. 25 (4), 681-693. doi:10.1210/me.2010-0232

Dimri, G. P., Lee, X., Basile, G., Acosta, M., Scott, G., Roskelley, C., et al. (1995). A Biomarker that Identifies Senescent Human Cells in Culture and in Aging Skin In Vivo. Proc. Natl. Acad. Sci. 92 (20), 9363-9367. doi:10.1073/pnas.92.20.9363

Düchler, M. (2012). G-quadruplexes: Targets and Tools in Anticancer Drug Design. J. Drug Target. 20 (5), 389-400. doi:10.3109/1061186x.2012.669384

Fay, M. M., Lyons, S. M., and Ivanov, P. (2017). RNA G-Quadruplexes in Biology: Principles and Molecular Mechanisms. J. Mol. Biol. 429 (14), 2127-2147. doi:10.1016/j.jmb.2017.05.017

Feng, M., Peng, H., Yao, R., Zhang, Z., Mao, G., Yu, H., et al. (2020). Inhibition of Cellular Communication Network Factor 1 (CCN1)-Driven Senescence Slows Down Cartilage Inflammaging and Osteoarthritis. Bone 139, 115522. doi:10.1016/j.bone.2020.115522

Goldberg, D. C., Fones, L., Vivinetto, A. L., Caufield, J. T., Ratan, R. R., and Cave, J. W. (2020). Manipulating Adult Neural Stem and Progenitor Cells with G-Quadruplex Ligands. ACS Chem. Neurosci. 11 (10), 1504-1518. doi:10.1021/ acschemneuro.0c00194

Graves, S. I., and Baker, D. J. (2020). Implicating Endothelial Cell Senescence to Dysfunction in the Ageing and Diseased Brain. Basic Clin. Pharmacol. Toxicol. 127 (2), 102-110. doi:10.1111/bcpt.13403

Guo, K., Gokhale, V., Hurley, L. H., and Sun, D. (2008). Intramolecularly Folded G-Quadruplex and I-Motif Structures in the Proximal Promoter of the Vascular Endothelial Growth Factor Gene. Nucleic Acids Res. 36 (14), 4598-4608. doi:10.1093/nar/gkn380

Hilfiker, A., Hilfiker-Kleiner, D., Fuchs, M., Kaminski, K., Lichtenberg, A., Rothkötter, H.-J., et al. (2002). Expression of CYR61, an Angiogenic Immediate Early Gene, in Arteriosclerosis and its Regulation by Angiotensin II. Circulation 106 (2), 254-260. doi:10.1161/01.cir.0000021426.87274.62

Hilfiker-Kleiner, D., Kaminski, K., Kaminska, A., Fuchs, M., Klein, G., Podewski, E., et al. (2004). Regulation of Proangiogenic Factor CCN1 in Cardiac Muscle. Circulation 109 (18), 2227-2233. doi:10.1161/01.cir.0000127952.90508.9d

Huang, F.-C., Chang, C.-C., Wang, J.-M., Chang, T.-C., and Lin, J.-J. (2012). Induction of Senescence in Cancer Cells by the G-Quadruplex Stabilizer, BMVC4, Is Independent of its Telomerase Inhibitory Activity. $\mathrm{Br}$. J. Pharmacol. 167 (2), 393-406. doi:10.1111/j.1476-5381.2012.01997.x

Jia, G., Aroor, A. R., Jia, C., and Sowers, J. R. (2019). Endothelial Cell Senescence in Aging-Related Vascular Dysfunction. Biochim. Biophys. Acta (Bba) - Mol. Basis Dis. 1865 (7), 1802-1809. doi:10.1016/j.bbadis.2018.08.008

Jun, J.-I., and Lau, L. F. (2017). CCN2 Induces Cellular Senescence in Fibroblasts. J. Cel Commun. Signal. 11 (1), 15-23. doi:10.1007/s12079-016-0359-1

Jun, J.-I., and Lau, L. F. (2010). The Matricellular Protein CCN1 Induces Fibroblast Senescence and Restricts Fibrosis in Cutaneous Wound Healing. Nat. Cel Biol 12 (7), 676-685. doi:10.1038/ncb2070

Khateb, S., Weisman-Shomer, P., Hershco-Shani, I., Ludwig, A. L., and Fry, M. (2007). The Tetraplex (CGG)n Destabilizing Proteins hnRNP A2 and CBF-A Enhance the In Vivo Translation of Fragile X Premutation mRNA. Nucleic Acids Res. 35 (17), 5775-5788. doi:10.1093/nar/gkm636

Kim, S.-M., Park, J.-H., Chung, S.-K., Kim, J.-Y., Hwang, H.-Y., Chung, K.-C., et al. (2004). Coxsackievirus B3 Infection Induces Cyr61 Activation via JNK to
Mediate Cell Death. J. Virol. 78 (24), 13479-13488. doi:10.1128/ jvi.78.24.13479-13488.2004

Kirkland, J. L., and Tchkonia, T. (2017). Cellular Senescence: A Translational Perspective. EBioMedicine 21, 21-28. doi:10.1016/j.ebiom.2017.04.013

Kiss, T., Nyúl-Tóth, Á., Balasubramanian, P., Tarantini, S., Ahire, C., DelFavero, J., et al. (2020). Single-cell RNA Sequencing Identifies Senescent Cerebromicrovascular Endothelial Cells in the Aged Mouse Brain. Geroscience 42 (2), 429-444. doi:10.1007/s11357-020-00177-1

Kivelä, R., Kyröläinen, H., Selänne, H., Komi, P. V., Kainulainen, H., and Vihko, V. (20071985). A Single Bout of Exercise with High Mechanical Loading Induces the Expression of Cyr61/CCN1 and CTGF/CCN2 in Human Skeletal Muscle. J. Appl. Physiol. 103 (4), 1395-1401. doi:10.1152/ japplphysiol.00531.2007

Koromilas, A. E., Lazaris-Karatzas, A., and Sonenberg, N. (1992). mRNAs Containing Extensive Secondary Structure in Their $5^{\prime}$ Non-coding Region Translate Efficiently in Cells Overexpressing Initiation Factor eIF-4E. EMBO J. 11 (11), 4153-4158. doi:10.1002/j.1460-2075.1992.tb05508.x

Kruisselbrink, E., Guryev, V., Brouwer, K., Pontier, D. B., Cuppen, E., and Tijsterman, M. (2008). Mutagenic Capacity of Endogenous G4 DNA Underlies Genome Instability in FANCJ-Defective C. elegans. Curr. Biol. 18 (12), 900-905. doi:10.1016/j.cub.2008.05.013

Kunz, M., Moeller, S., Koczan, D., Lorenz, P., Wenger, R. H., Glocker, M. O., et al. (2003). Mechanisms of Hypoxic Gene Regulation of Angiogenesis Factor Cyr61 in Melanoma Cells. J. Biol. Chem. 278 (46), 45651-45660. doi:10.1074/ jbc.m301373200

Kurozumi, K., Hardcastle, J., Thakur, R., Shroll, J., Nowicki, M., Otsuki, A., et al. (2008). Oncolytic HSV-1 Infection of Tumors Induces Angiogenesis and Upregulates CYR61. Mol. Ther. 16 (8), 1382-1391. doi:10.1038/mt.2008.112

Kwok, C. K., Marsico, G., Sahakyan, A. B., Chambers, V. S., and Balasubramanian, S. (2016). rG4-seq Reveals Widespread Formation of G-Quadruplex Structures in the Human Transcriptome. Nat. Methods 13 (10), 841-844. doi:10.1038/ nmeth.3965

Lähteenvuo, J., and Rosenzweig, A. (2012). Effects of Aging on Angiogenesis. Circ. Res. 110 (9), 1252-1264. doi:10.1161/circresaha.111.246116

Lee, S., Ahad, A., Luu, M., Moon, S., Caesar, J., Cardoso, W. V., et al. (2019). CCN1Yes-Associated Protein Feedback Loop Regulates Physiological and Pathological Angiogenesis. Mol. Cel Biol 39 (18), e00107-19. doi:10.1128/ MCB.00107-19

Lee, Y.-K., Uchida, H., Smith, H., Ito, A., and Sanchez, T. (2019). The Isolation and Molecular Characterization of Cerebral Microvessels. Nat. Protoc. 14 (11), 3059-3081. doi:10.1038/s41596-019-0212-0

Lejault, P., Moruno-Manchon, J. F., Vemu, S. M., Honarpisheh, P., Zhu, L., Kim, N., et al. (2020). Regulation of Autophagy by DNA G-Quadruplexes. Autophagy 16 (12), 2252-2259. doi:10.1080/15548627.2020.1769991

Li, X., Xu, M., Pitzer, A. L., Xia, M., Boini, K. M., Li, P.-L., et al. (2014). Control of Autophagy Maturation by Acid Sphingomyelinase in Mouse Coronary Arterial Smooth Muscle Cells: Protective Role in Atherosclerosis. J. Mol. Med. 92 (5), 473-485. doi:10.1007/s00109-014-1120-y

Luo, Z., Xu, W., Ma, S., Qiao, H., Gao, L., Zhang, R., et al. (2017). Moderate Autophagy Inhibits Vascular Smooth Muscle Cell Senescence to Stabilize Progressed Atherosclerotic Plaque via the mTORC1/ULK1/ATG13 Signal Pathway. Oxid Med. Cel Longev 2017, 3018190. doi:10.1155/2017/3018190

Makrides, S. C. (1983). Protein Synthesis and Degradation During Aging and Senescence. Biol. Rev. 58 (3), 343-422. doi:10.1111/j.1469-185x.1983.tb00394.x

Merz, A. A., and Cheng, S. (2016). Sex Differences in Cardiovascular Ageing. Heart 102 (11), 825-831. doi:10.1136/heartjnl-2015-308769

Moreno-Blas, D., Gorostieta-Salas, E., Pommer-Alba, A., Muciño-Hernández, G., Gerónimo-Olvera, C., Maciel-Barón, L. A., et al. (2019). Cortical Neurons Develop a Senescence-like Phenotype Promoted by Dysfunctional Autophagy. Aging 11 (16), 6175-6198. doi:10.18632/ aging.102181

Moruno-Manchon, J. F., Lejault, P., Wang, Y., McCauley, B., Honarpisheh, P., Morales Scheihing, D. A., et al. (2020). Small-molecule G-Quadruplex Stabilizers Reveal a Novel Pathway of Autophagy Regulation in Neurons. Elife 9, e52283. doi:10.7554/eLife.52283

Moruno-Manchon, J. F., Koellhoffer, E. C., Gopakumar, J., Hambarde, S., Kim, N., McCullough, L. D., et al. (2017). The G-Quadruplex DNA Stabilizing Drug Pyridostatin Promotes DNA Damage and Downregulates 
Transcription of Brcal in Neurons. Aging 9 (9), 1957-1970. doi:10.18632/ aging. 101282

Nakagawa, Y., Minato, M., Sumiyoshi, K., Maeda, A., Hara, C., Murase, Y., et al. (2013). Regulation of CCN1 via the $3^{\prime}$-untranslated Region. J. Cel Commun. Signal. 7 (3), 207-217. doi:10.1007/s12079-013-0202-x

Noubissi, F. K., McBride, A. A., Leppert, H. G., Millet, L. J., Wang, X., and Davern, S. M. (2021). Detection and Quantification of $\gamma$-H2AX Using a Dissociation Enhanced Lanthanide Fluorescence Immunoassay. Sci. Rep. 11 (1), 8945. doi:10.1038/s41598-021-88296-3

O’Brien, T. P., Yang, G. P., Sanders, L., and Lau, L. F. (1990). Expression of Cyr61, a Growth Factor-Inducible Immediate-Early Gene. Mol. Cel. Biol. 10 (7), 3569-3577. doi:10.1128/mcb.10.7.3569

Oh, K. S., Febres-Aldana, C. A., Kuritzky, N., Ujueta, F., Arenas, I. A., Sriganeshan, V., et al. (2021). Cellular Senescence Evaluated by P16INK4a Immunohistochemistry Is a Prevalent Phenomenon in Advanced Calcific Aortic Valve Disease. Cardiovasc. Pathol. 52, 107318. doi:10.1016/j.carpath.2021.107318

Pelegrí, C., Canudas, A. M., del Valle, J., Casadesus, G., Smith, M. A., Camins, A., et al. (2007). Increased Permeability of Blood-Brain Barrier on the hippocampus of a Murine Model of Senescence. Mech. Ageing Development 128 (9), 522-528. doi:10.1016/j.mad.2007.07.002

Pelletier, J., and Sonenberg, N. (1985). Insertion Mutagenesis to Increase Secondary Structure within the $5^{\prime}$ Noncoding Region of a Eukaryotic mRNA Reduces Translational Efficiency. Cell 40 (3), 515-526. doi:10.1016/0092-8674(85)90200-4

Perrière, N., Demeuse, P., Garcia, E., Regina, A., Debray, M., Andreux, J.-P., et al. (2005). Puromycin-based Purification of Rat Brain Capillary Endothelial Cell Cultures. Effect on the Expression of Blood-Brain Barrier-specific Properties. J. Neurochem. 93 (2), 279-289. doi:10.1111/j.1471-4159.2004.03020.x

Pinçon, A., De Montgolfier, O., Akkoyunlu, N., Daneault, C., Pouliot, P., Villeneuve, L., et al. (2019). Non-Alcoholic Fatty Liver Disease, and the Underlying Altered Fatty Acid Metabolism, Reveals Brain Hypoperfusion and Contributes to the Cognitive Decline in APP/PS1 Mice. Metabolites 9 (5), 104. doi:10.3390/metabo9050104

Quan, T., He, T., Shao, Y., Lin, L., Kang, S., Voorhees, J. J., et al. (2006). Elevated Cysteine-Rich 61 Mediates Aberrant Collagen Homeostasis in Chronologically Aged and Photoaged Human Skin. Am. J. Pathol. 169 (2), 482-490. doi:10.2353/ ajpath.2006.060128

Rajendran, P., Alzahrani, A. M., Hanieh, H. N., Kumar, S. A., Ben Ammar, R., Rengarajan, T., et al. (2019). Autophagy and Senescence: A New Insight in Selected Human Diseases. J. Cel Physiol 234 (12), 21485-21492. doi:10.1002/jcp.28895

Reid, S. E., Kay, E. J., Neilson, L. J., Henze, A. T., Serneels, J., McGhee, E. J., et al. (2017). Tumor Matrix Stiffness Promotes Metastatic Cancer Cell Interaction with the Endothelium. EMBO J. 36 (16), 2373-2389. doi:10.15252/embj.201694912

Renaud de la Faverie, A., Guédin, A., Bedrat, A., Yatsunyk, L. A., and Mergny, J.-L. (2014). Thioflavin T as a Fluorescence Light-Up Probe for G4 Formation. Nucleic Acids Res. 42 (8), e65. doi:10.1093/nar/gku111

Rey, S., Quintavalle, C., Burmeister, K., Calabrese, D., Schlageter, M., Quagliata, L., et al. (2017). Liver Damage and Senescence Increases in Patients Developing Hepatocellular Carcinoma. J. Gastroenterol. Hepatol. 32 (8), 1480-1486. doi:10.1111/jgh.13717

Riccardi, C., Napolitano, E., Platella, C., Musumeci, D., Melone, M. A. B., and Montesarchio, D. (2021). Anti-VEGF DNA-based Aptamers in Cancer Therapeutics and Diagnostics. Med. Res. Rev. 41 (1), 464-506. doi:10.1002/ med.21737

Riou, J. F., Guittat, L., Mailliet, P., Laoui, A., Renou, E., Petitgenet, O., et al. (2002). Cell Senescence and Telomere Shortening Induced by a New Series of Specific G-Quadruplex DNA Ligands. Proc. Natl. Acad. Sci. 99 (5), 2672-2677. doi:10.1073/pnas.052698099

Salazar, G., Cullen, A., Huang, J., Zhao, Y., Serino, A., Hilenski, L., et al. (2020). SQSTM1/p62 and PPARGC1A/PGC-1alpha at the Interface of Autophagy and Vascular Senescence. Autophagy 16 (6), 1092-1110. doi:10.1080/ 15548627.2019.1659612

Sanders, P. G. T., Cotterell, J., Sharpe, J., and Isalan, M. (2013). Transfecting RNA Quadruplexes Results in Few Transcriptome Perturbations. RNA Biol. 10 (2), 205-210. doi:10.4161/rna.22781

Schaeffer, C., Bardoni, B., Mandel, J. L., Ehresmann, B., Ehresmann, C., and Moine, H. (2001). The Fragile X Mental Retardation Protein Binds Specifically to its mRNA via a Purine Quartet Motif. EMBO J. 20 (17), 4803-4813. doi:10.1093/ emboj/20.17.4803
Schumacher, B., Pothof, J., Vijg, J., and Hoeijmakers, J. H. J. (2021). The Central Role of DNA Damage in the Ageing Process. Nature 592 (7856), 695-703. doi:10.1038/s41586-021-03307-7

Seetlani, N. K., Kumar, N., Imran, K., Ali, A., Shams, N., and Sheikh, T. (2016). Alzheimer and Vascular Dementia in the Elderly Patients. Pak J. Med. Sci. 32 (5), 1286-1290. doi:10.12669/pjms.325.10792

Siddiqui-Jain, A., Grand, C. L., Bearss, D. J., and Hurley, L. H. (2002). Direct Evidence for a G-Quadruplex in a Promoter Region and its Targeting with a Small Molecule to Repress C-MYC Transcription. Proc. Natl. Acad. Sci. 99 (18), 11593-11598. doi:10.1073/pnas.182256799

Simmnacher, K., Krach, F., Schneider, Y., Alecu, J. E., Mautner, L., Klein, P., et al. (2020). Unique Signatures of Stress-Induced Senescent Human Astrocytes. Exp. Neurol. 334, 113466. doi:10.1016/j.expneurol.2020.113466

Sonenberg, N., and Hinnebusch, A. G. (2009). Regulation of Translation Initiation in Eukaryotes: Mechanisms and Biological Targets. Cell 136 (4), 731-745. doi:10.1016/j.cell.2009.01.042

Song, H. W., Foreman, K. L., Gastfriend, B. D., Kuo, J. S., Palecek, S. P., and Shusta, E. V. (2020). Transcriptomic Comparison of Human and Mouse Brain Microvessels. Sci. Rep. 10 (1), 12358. doi:10.1038/s41598-020-69096-7

Song, J., Perreault, J.-P., Topisirovic, I., and Richard, S. (2016). RNA G-Quadruplexes and Their Potential Regulatory Roles in Translation. Translation 4 (2), e1244031. doi:10.1080/21690731.2016.1244031

Subramanian, M., Rage, F., Tabet, R., Flatter, E., Mandel, J. L., and Moine, H. (2011). G-quadruplex RNA Structure as a Signal for Neurite mRNA Targeting. EMBO Rep. 12 (7), 697-704. doi:10.1038/embor.2011.76

Sun, D., Guo, K., Rusche, J. J., and Hurley, L. H. (2005). Facilitation of a Structural Transition in the Polypurine/polypyrimidine Tract within the Proximal Promoter Region of the Human VEGF Gene by the Presence of Potassium and G-Quadruplex-Interactive Agents. Nucleic Acids Res. 33 (18), 6070-6080. doi:10.1093/nar/gki917

Sun, D., Liu, W.-J., Guo, K., Rusche, J. J., Ebbinghaus, S., Gokhale, V., et al. (2008). The Proximal Promoter Region of the Human Vascular Endothelial Growth Factor Gene Has a G-Quadruplex Structure that Can Be Targeted by G-Quadruplex-Interactive Agents. Mol. Cancer Ther. 7 (4), 880-889. doi:10.1158/1535-7163.mct-07-2119

Sunderland, P., Augustyniak, J., Lenart, J., Bużańska, L., Carlessi, L., Delia, D., et al. (2020). ATM-deficient Neural Precursors Develop Senescence Phenotype with Disturbances in Autophagy. Mech. Ageing Development 190, 111296. doi:10.1016/j.mad.2020.111296

Tabor, N., Ngwa, C., Mitteaux, J., Meyer, M. D., Moruno-Manchon, J. F., Zhu, L., et al. (2021). Differential Responses of Neurons, Astrocytes, and Microglia to G-Quadruplex Stabilization. Aging 13 (12), 15917-15941. doi:10.18632/aging.203222

Tchkonia, T., Zhu, Y., van Deursen, J., Campisi, J., and Kirkland, J. L. (2013). Cellular Senescence and the Senescent Secretory Phenotype: Therapeutic Opportunities. J. Clin. Invest. 123 (3), 966-972. doi:10.1172/jci64098

Técher, H., Koundrioukoff, S., Nicolas, A., and Debatisse, M. (2017). The Impact of Replication Stress on Replication Dynamics and DNA Damage in Vertebrate Cells. Nat. Rev. Genet. 18 (9), 535-550. doi:10.1038/nrg.2017.46

Teng, F.-Y., Wang, T.-T., Guo, H.-L., Xin, B.-G., Sun, B., Dou, S.-X., et al. (2020). The HRDC Domain Oppositely Modulates the Unwinding Activity of E. coli RecQ Helicase on Duplex DNA and G-Quadruplex. J. Biol. Chem. 295 (51), 17646-17658. doi:10.1074/jbc.ra120.015492

Valle, J., Duran-Vilaregut, J., Manich, G., Camins, A., Pallàs, M., Vilaplana, J., et al. (2009). Time-course of Blood-Brain Barrier Disruption in Senescenceaccelerated Mouse Prone 8 (SAMP8) Mice. Int. J. Dev. Neurosci. 27 (1), 47-52. doi:10.1016/j.ijdevneu.2008.10.002

Wang, F., Cao, Y., Ma, L., Pei, H., Rausch, W. D., and Li, H. (2018). Dysfunction of Cerebrovascular Endothelial Cells: Prelude to Vascular Dementia. Front. Aging Neurosci. 10, 376. doi:10.3389/fnagi.2018.00376

Wiedmaier, N., Müller, S., Köberle, M., Manncke, B., Krejci, J., Autenrieth, I. B., et al. (2008). Bacteria Induce CTGF and CYR61 Expression in Epithelial Cells in a Lysophosphatidic Acid Receptor-dependent Manner. Int. J. Med. Microbiol. 298 (3-4), 231-243. doi:10.1016/j.ijmm.2007.06.001

Wolters, F. J., and Ikram, M. A. (2019). Epidemiology of Vascular Dementia. Atvb 39 (8), 1542-1549. doi:10.1161/atvbaha.119.311908

Xu, S., Li, Q., Xiang, J., Yang, Q., Sun, H., Guan, A., et al. (2016). Thioflavin T as an Efficient Fluorescence Sensor for Selective Recognition of RNA G-Quadruplexes. Sci. Rep. 6, 24793. doi:10.1038/srep24793 
Yamazaki, Y., Baker, D. J., Tachibana, M., Liu, C.-C., van Deursen, J. M., Brott, T. G., et al. (2016). Vascular Cell Senescence Contributes to Blood-Brain Barrier Breakdown. Stroke 47 (4), 1068-1077. doi:10.1161/strokeaha.115.010835

Yang, T., Sun, Y., Lu, Z., Leak, R. K., and Zhang, F. (2017). The Impact of Cerebrovascular Aging on Vascular Cognitive Impairment and Dementia. Ageing Res. Rev. 34, 15-29. doi:10.1016/j.arr.2016.09.007

Zhang, J., Harvey, S. E., and Cheng, C. (2019). A High-Throughput Screen Identifies Small Molecule Modulators of Alternative Splicing by Targeting RNA G-Quadruplexes. Nucleic Acids Res. 47 (7), 3667-3679. doi:10.1093/nar/gkz036

Zhang, S., Sun, H., Chen, H., Li, Q., Guan, A., Wang, L., et al. (2018). Direct Visualization of Nucleolar G-Quadruplexes in Live Cells by Using a Fluorescent Light-Up Probe. Biochim. Biophys. Acta (Bba) - Gen. Subjects 1862 (5), 1101-1106. doi:10.1016/j.bbagen.2018.01.022

Zhang, X., Li, G., Guo, L., Nie, K., Jia, Y., Zhao, L., et al. (2013). Age-related Alteration in Cerebral Blood Flow and Energy Failure Is Correlated with Cognitive Impairment in the Senescence-Accelerated Prone Mouse Strain 8 (SAMP8). Neurol. Sci. 34 (11), 1917-1924. doi:10.1007/s10072-0131407-8
Conflict of Interest: The authors declare that the research was conducted in the absence of any commercial or financial relationships that could be construed as a potential conflict of interest.

Publisher's Note: All claims expressed in this article are solely those of the authors and do not necessarily represent those of their affiliated organizations, or those of the publisher, the editors and the reviewers. Any product that may be evaluated in this article, or claim that may be made by its manufacturer, is not guaranteed or endorsed by the publisher.

Copyright (c) 2022 Noh, Blasco-Conesa, Lai, Ganesh, Urayama, Moreno-Gonzalez, Marrelli, McCullough and Moruno-Manchon. This is an open-access article distributed under the terms of the Creative Commons Attribution License (CC $B Y)$. The use, distribution or reproduction in other forums is permitted, provided the original author(s) and the copyright owner(s) are credited and that the original publication in this journal is cited, in accordance with accepted academic practice. No use, distribution or reproduction is permitted which does not comply with these terms. 